\title{
Synthetic access to all four stereoisomers of oxetin
}

\author{
Ahmad F. Kassir, ${ }^{\ddagger}$ Sherif S. Ragab, ${ }^{\mathrm{f},}$ Thao A. M. Nguyen, ${ }^{\mathrm{f}}$ Florence Charnay-Pouget ${ }^{\mathrm{f}}$ \\ Régis Guillot, ${ }^{\mathrm{I}}$ Marie-Christine Scherrmann, ${ }^{\mathrm{f}}$ Thomas Boddaert ${ }^{ }$and David J. \\ Aitken $^{\mathrm{H}, *}$ \\ ${ }^{\text {I }}$ CP3A Organic Synthesis Group, ICMMO, UMR CNRS 8182, Université Paris Sud, Université Paris \\ Saclay, 15 rue Georges Clemenceau, 91405 Orsay Cedex, France. \\ ${ }^{\ddagger}$ Photochemistry Department, Chemical Industries Research Division, National Research Centre, P.O. Box \\ 12622, Dokki, Giza, Egypt. \\ ' Services Communs, ICMMO, UMR CNRS 8182, Université Paris Sud, Université Paris Saclay, 15 rue \\ Georges Clemenceau, 91405 Orsay Cedex, France.
}

Supporting Information

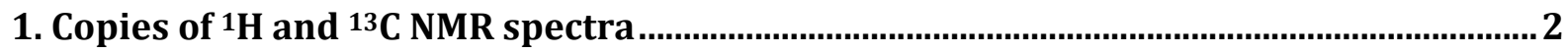

2. X-ray structure analysis of compounds 12ab2 and 12bb2 ….......................................... 34

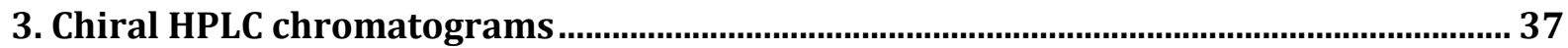




\section{Copies of ${ }^{1} \mathrm{H}$ and ${ }^{13} \mathrm{C}$ NMR spectra}
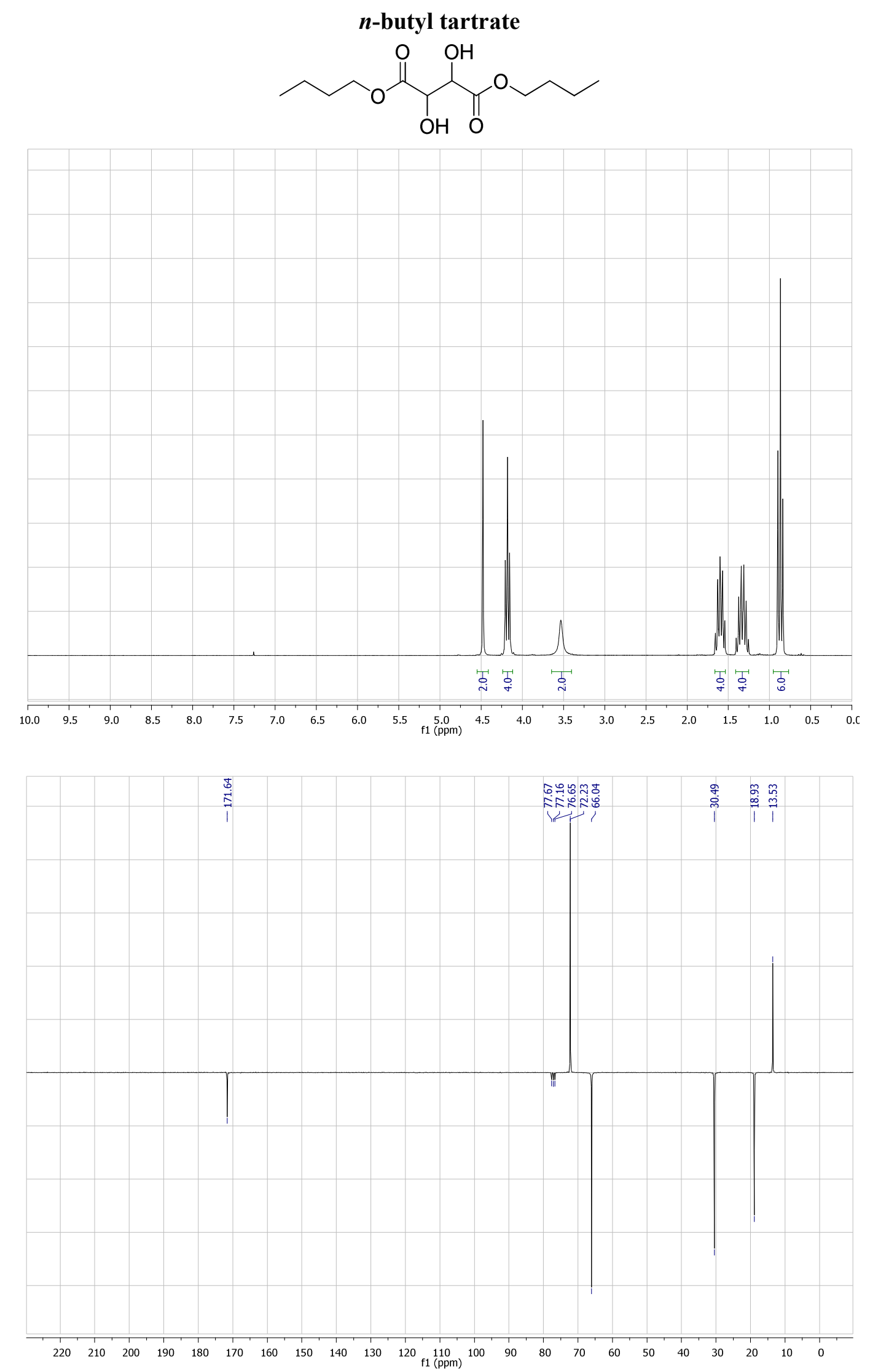
n-butyl glyoxylate<smiles>CCCCOC(=O)C=O</smiles>

3a
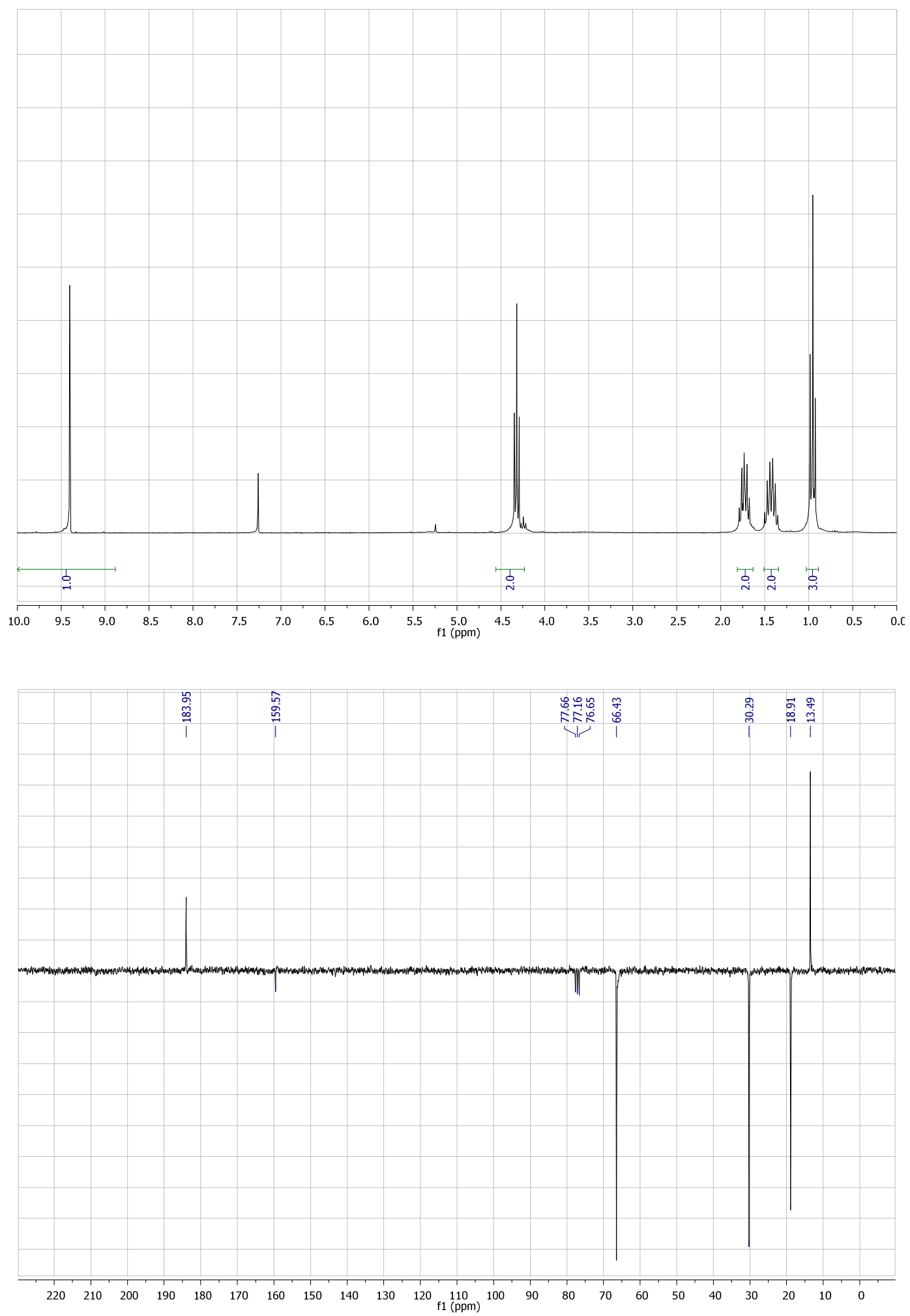

S3 


\section{tert-butyl formyl(vinyl)carbamate}

$\mathrm{N}^{-\mathrm{CHO}}$

2b Boc
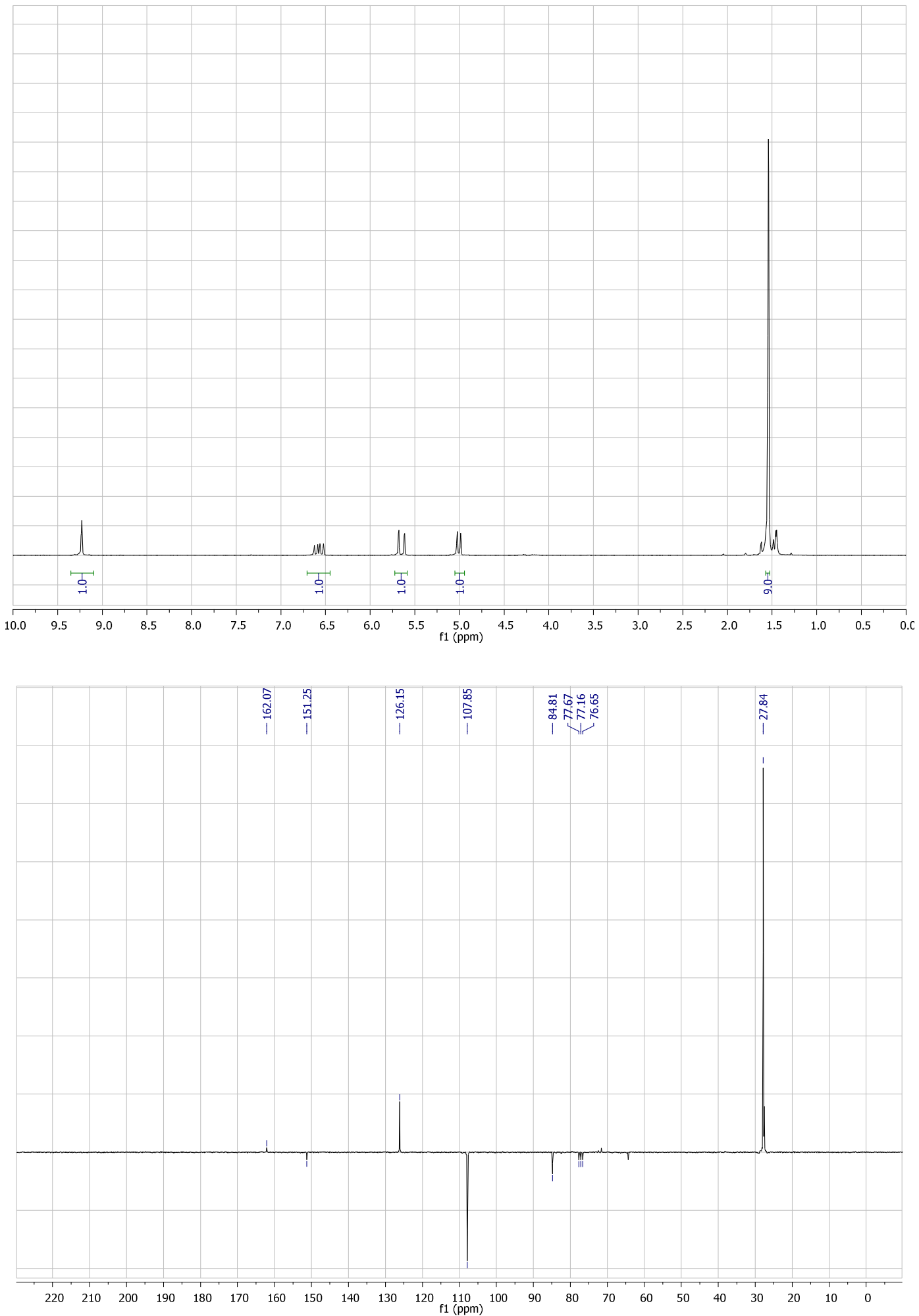


\section{tert-butyl vinylcarbamate}
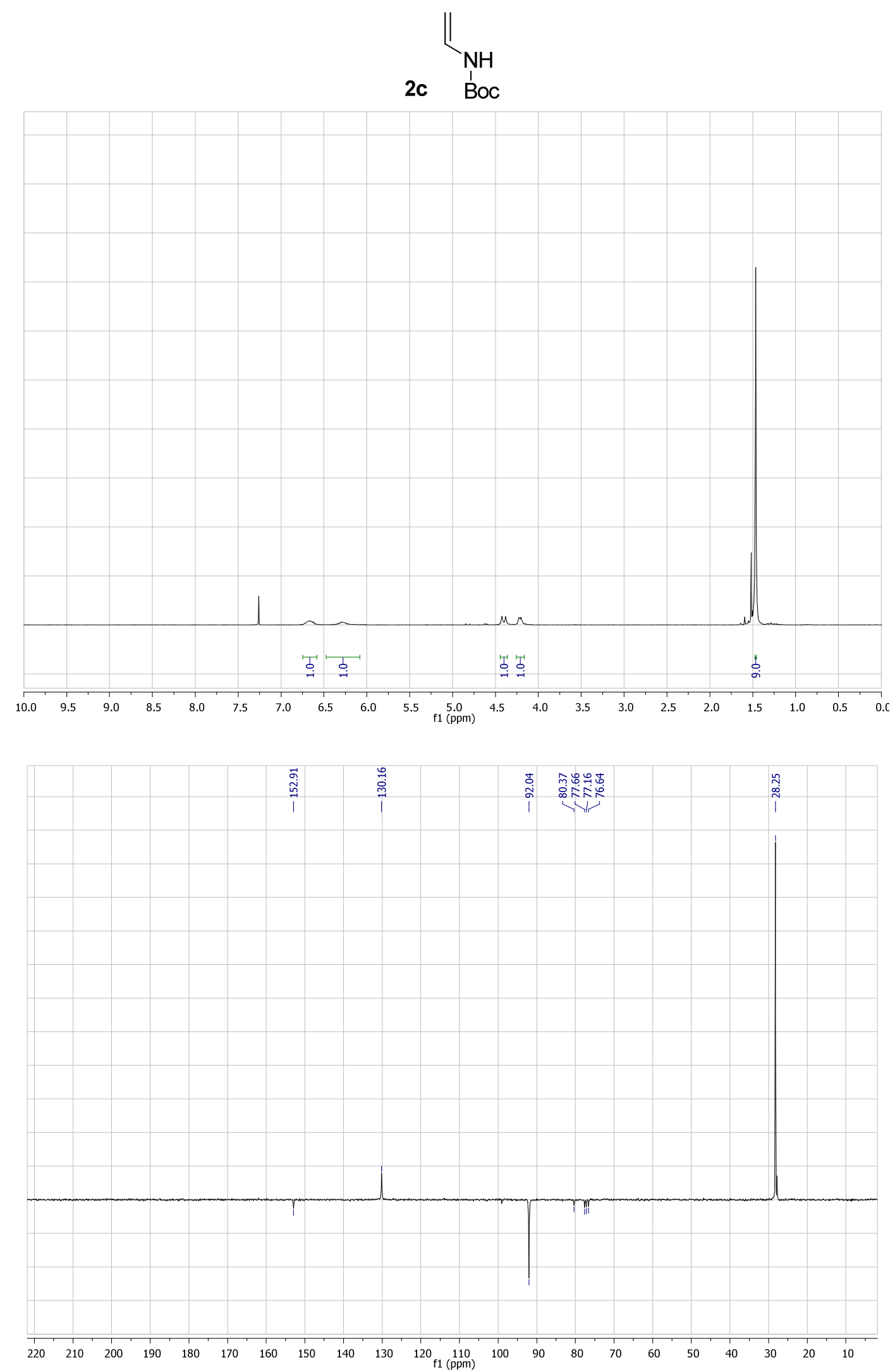
Racemic cis and trans $n$-butyl 3-formamidooxetane-2-carboxylate

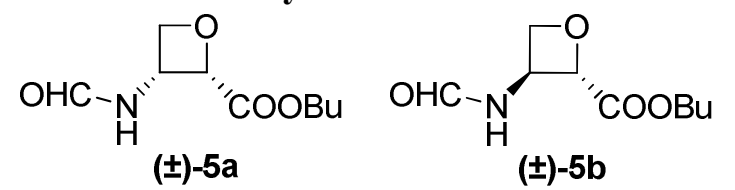

Analyses were made on an unseparated mixture of both $\mathbf{5 a}: \mathbf{5} \mathbf{b}=0.83: 1$
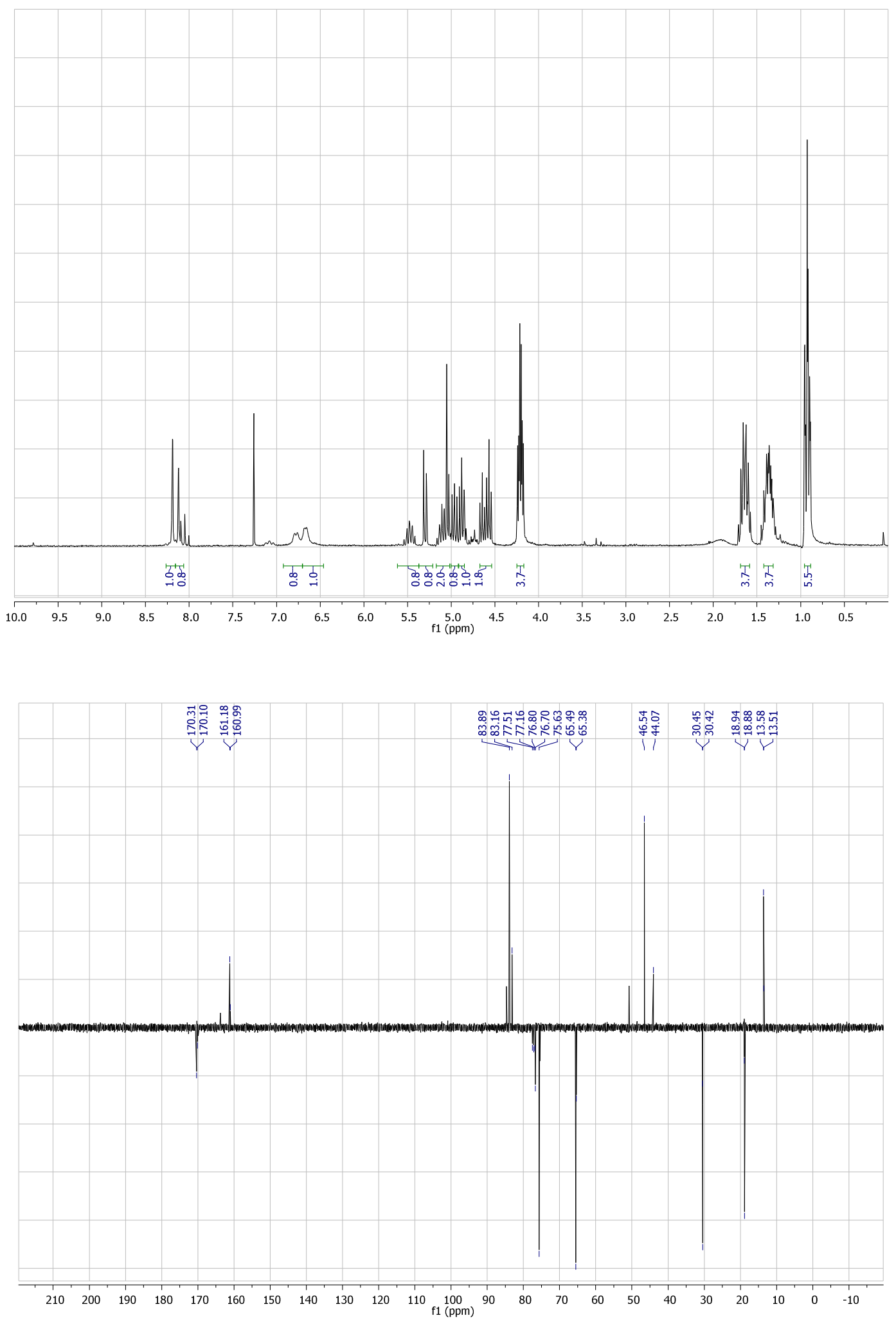
Racemic cis and trans methyl 3-formamidooxetane-2-carboxylate

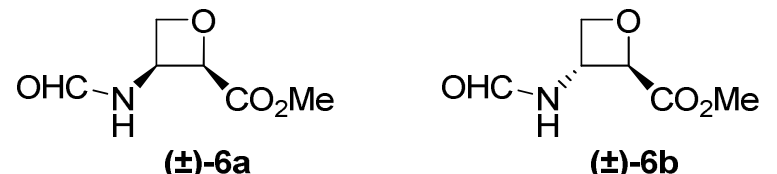

Analyses were made on an unseparated mixture of both $\mathbf{6 a}: \mathbf{6 b}=1: 2.4$
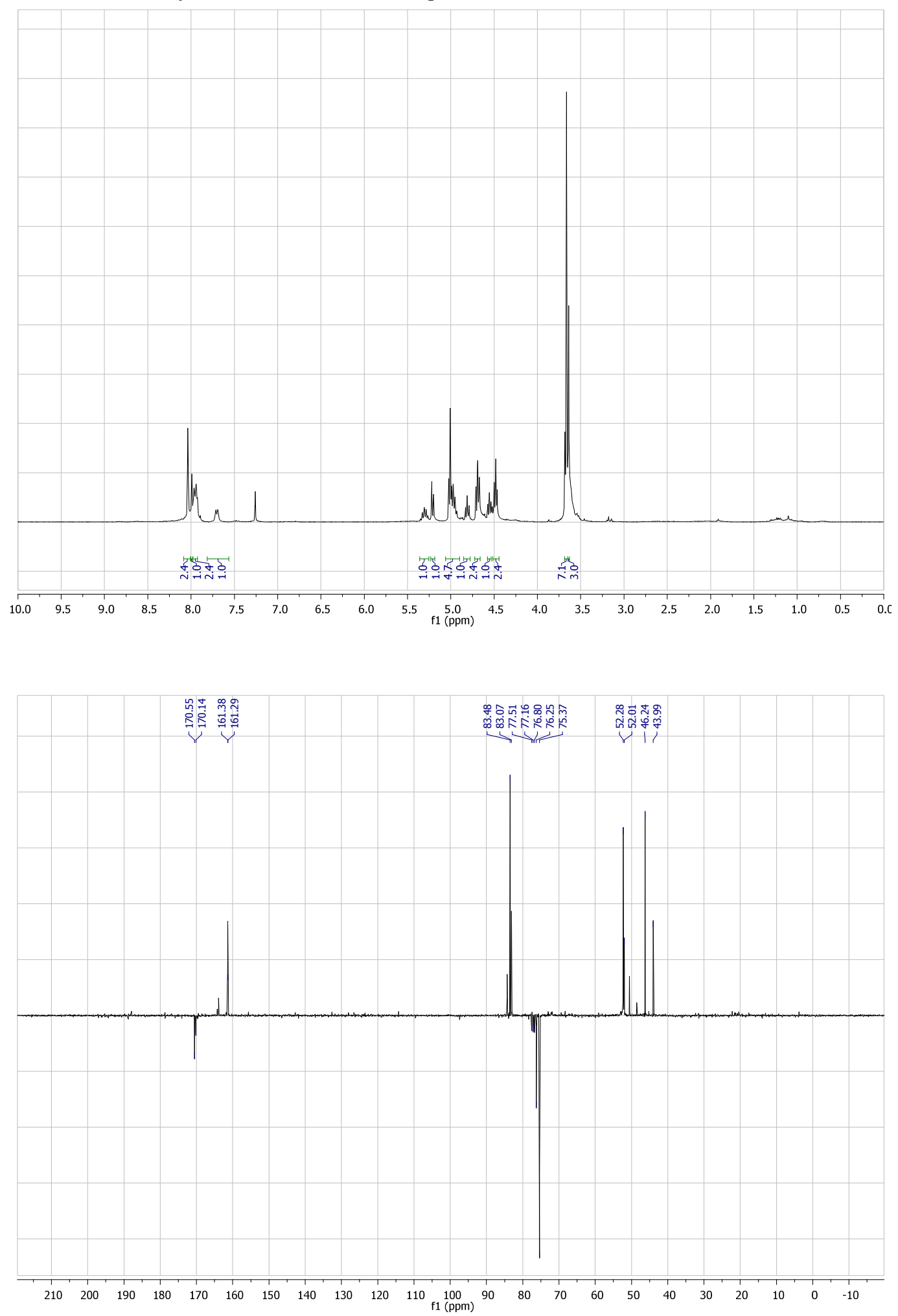
Racemic cis and trans tert-butyl 3-formamidooxetane-2-carboxylate<smiles>CC(C)(C)OC1OCC1NC=O</smiles>

$( \pm)-7 a$

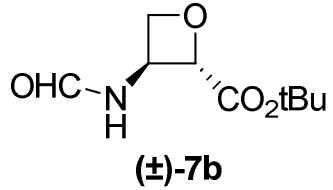

$( \pm)-7 b$

Analyses were made on an unseparated and indistinguishable mixture of both $\mathbf{7 a : 7 b}=1: 1$
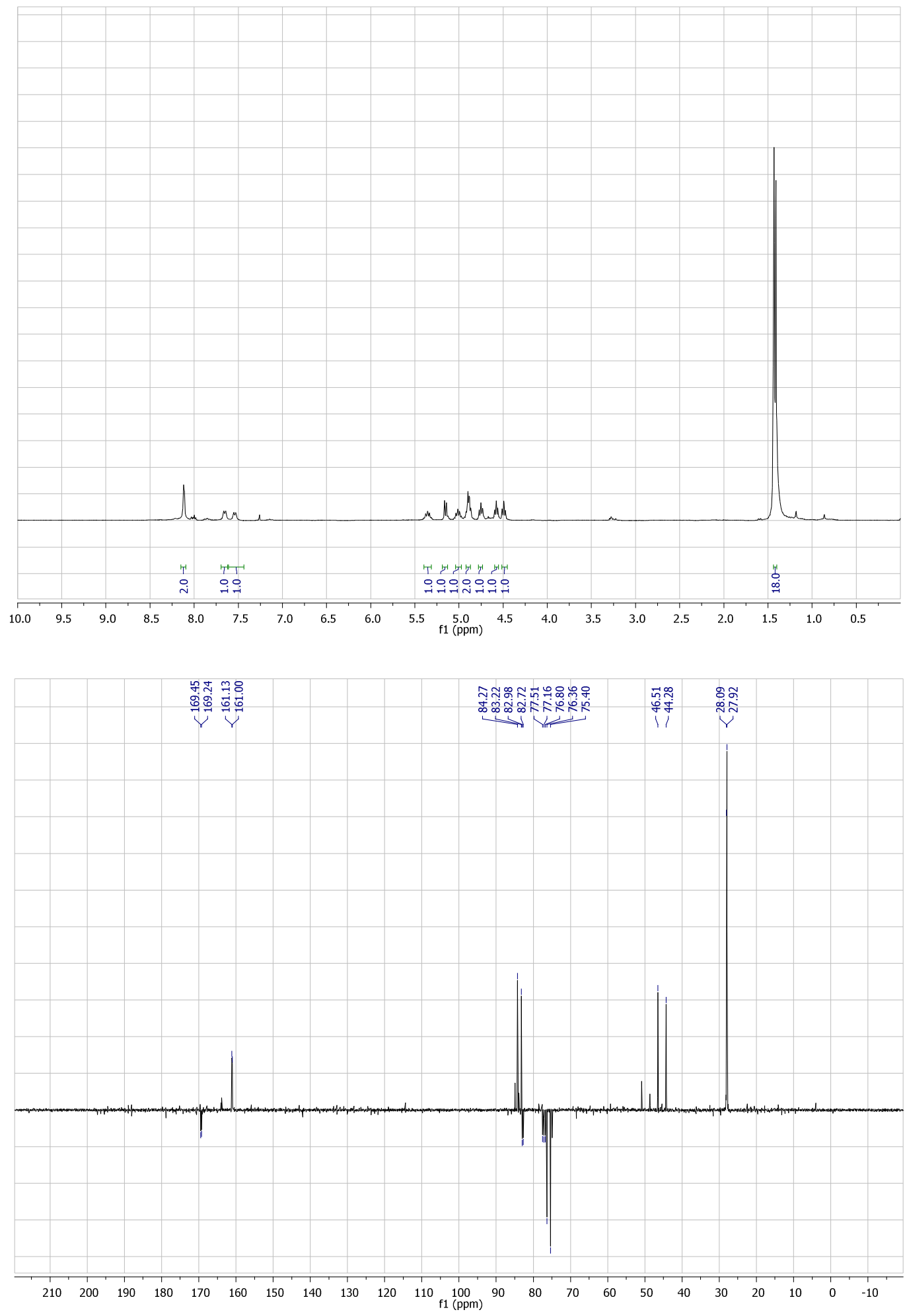
Racemic cis $n$-butyl 3-(N-(tert-butoxycarbonyl)formamido)oxetane-2-carboxylate (prepared according to Table 3, entry 4)

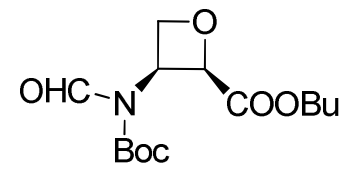

$(\mathbf{t})-\mathbf{8 a}$
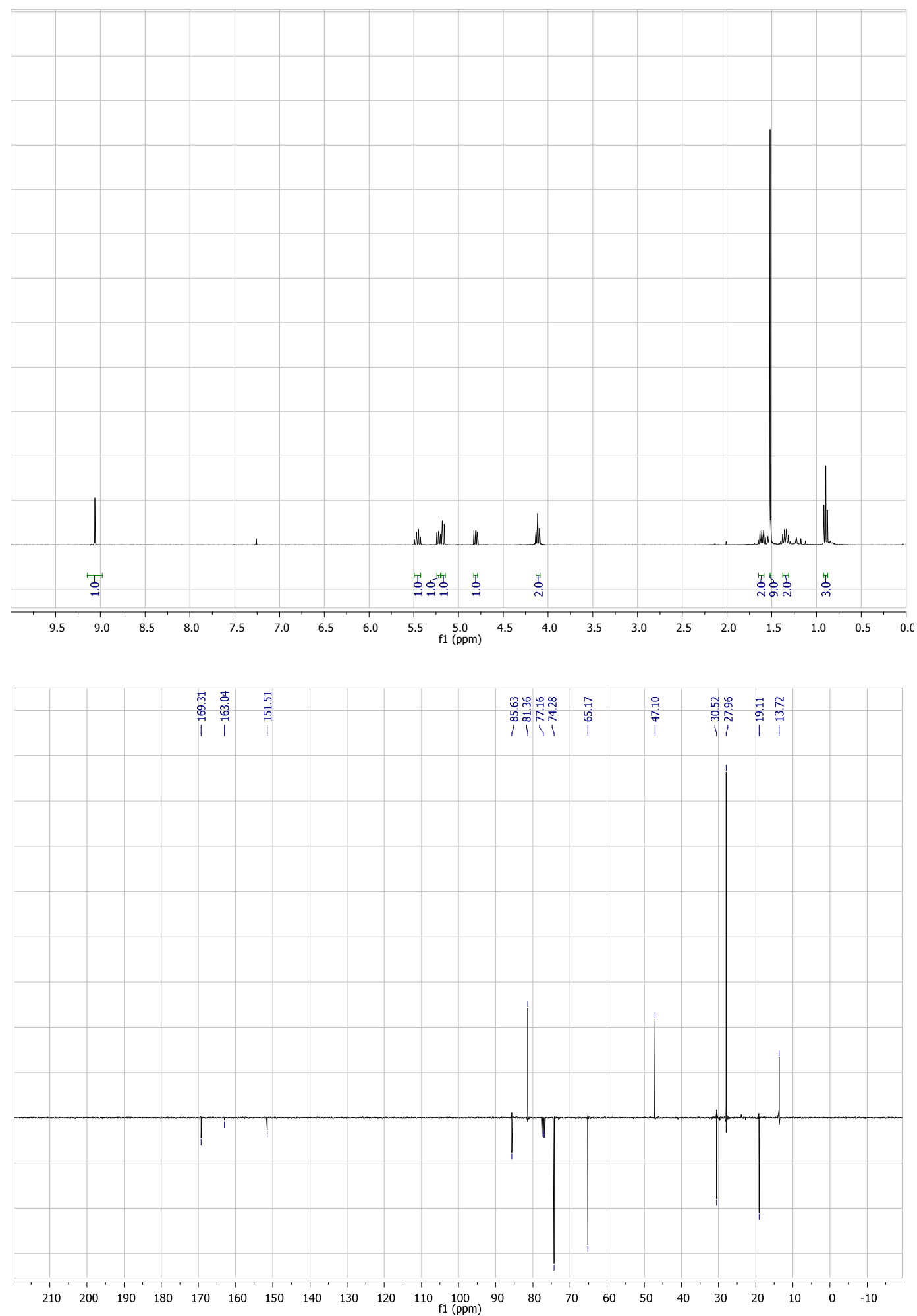
Racemic trans $n$-butyl 3-(N-(tert-butoxycarbonyl)formamido)oxetane-2-carboxylate (prepared according to Table 3, entry 4)

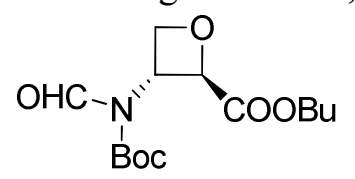

$( \pm)-8 b$
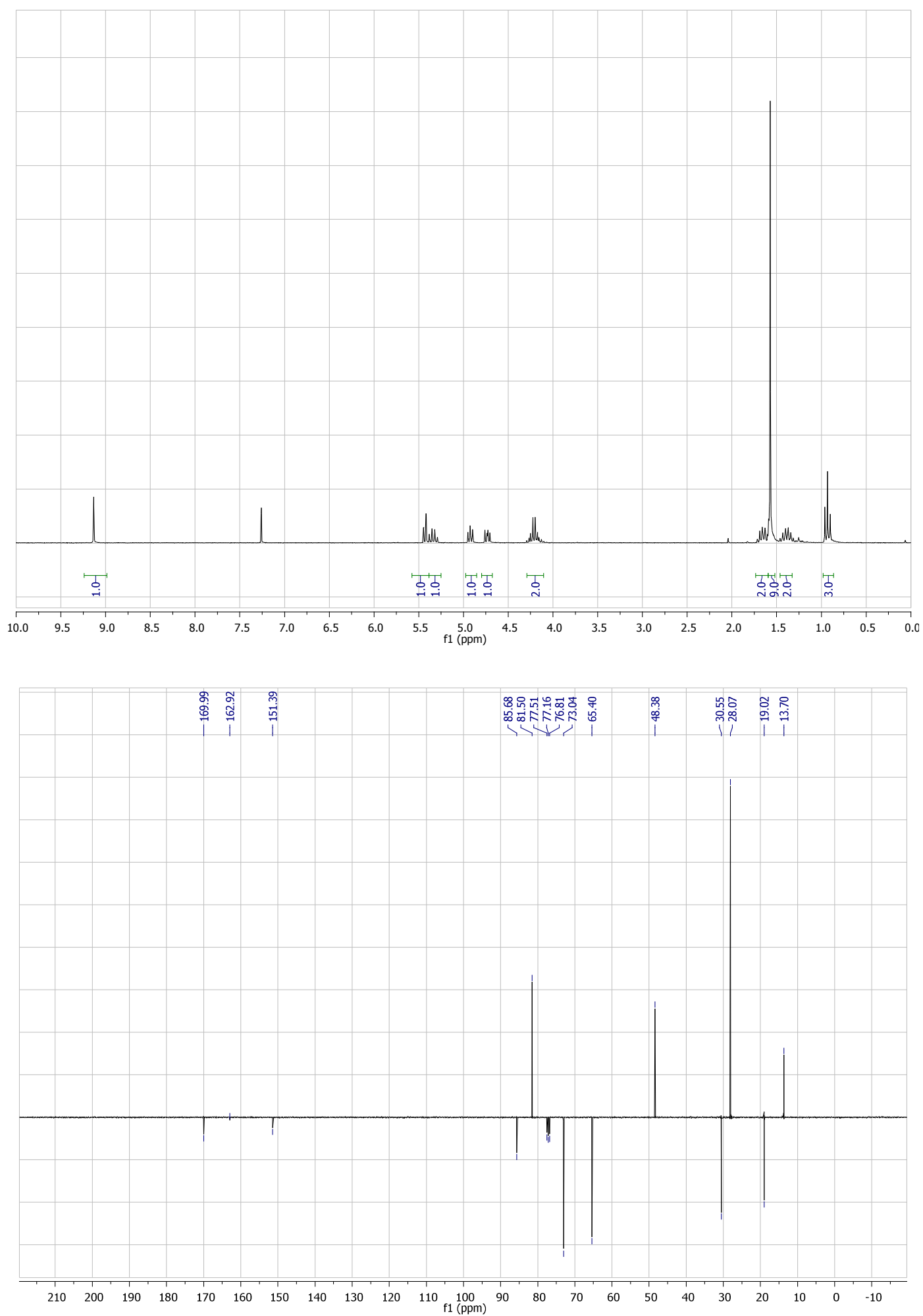
Racemic cis $n$-butyl 3-(N-(tert-butoxycarbonyl)formamido)oxetane-2-carboxylate (prepared according to Scheme 2)

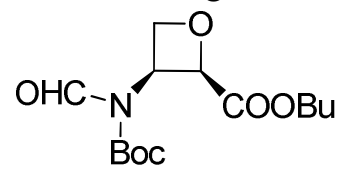

(士)-8a

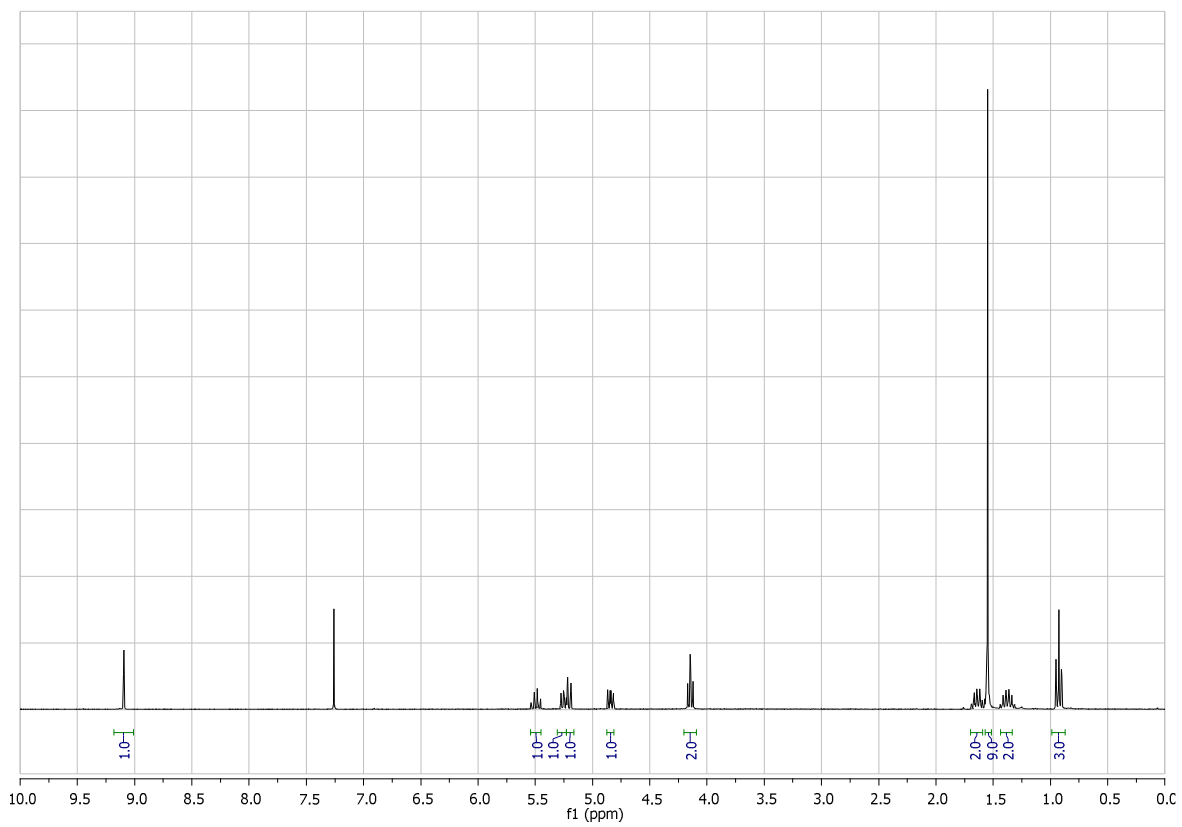

Racemic trans $n$-butyl 3-(N-(tert-butoxycarbonyl)formamido)oxetane-2-carboxylate (prepared according to Scheme 2)

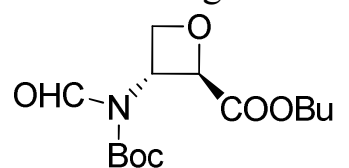

$( \pm)-8 b$

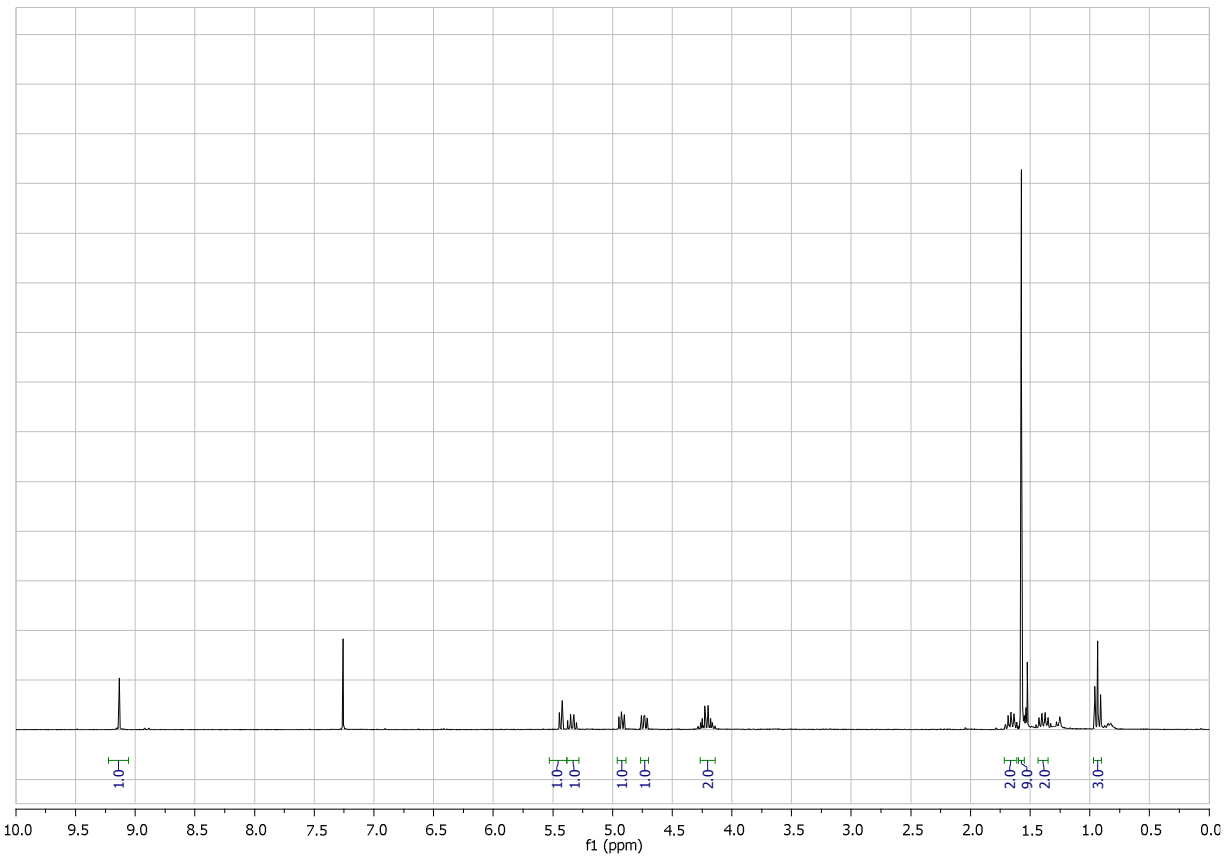


Racemic cis 3-((tert-butoxycarbonyl)amino)oxetane-2-carboxylic acid

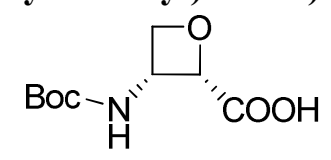

(士)-9a
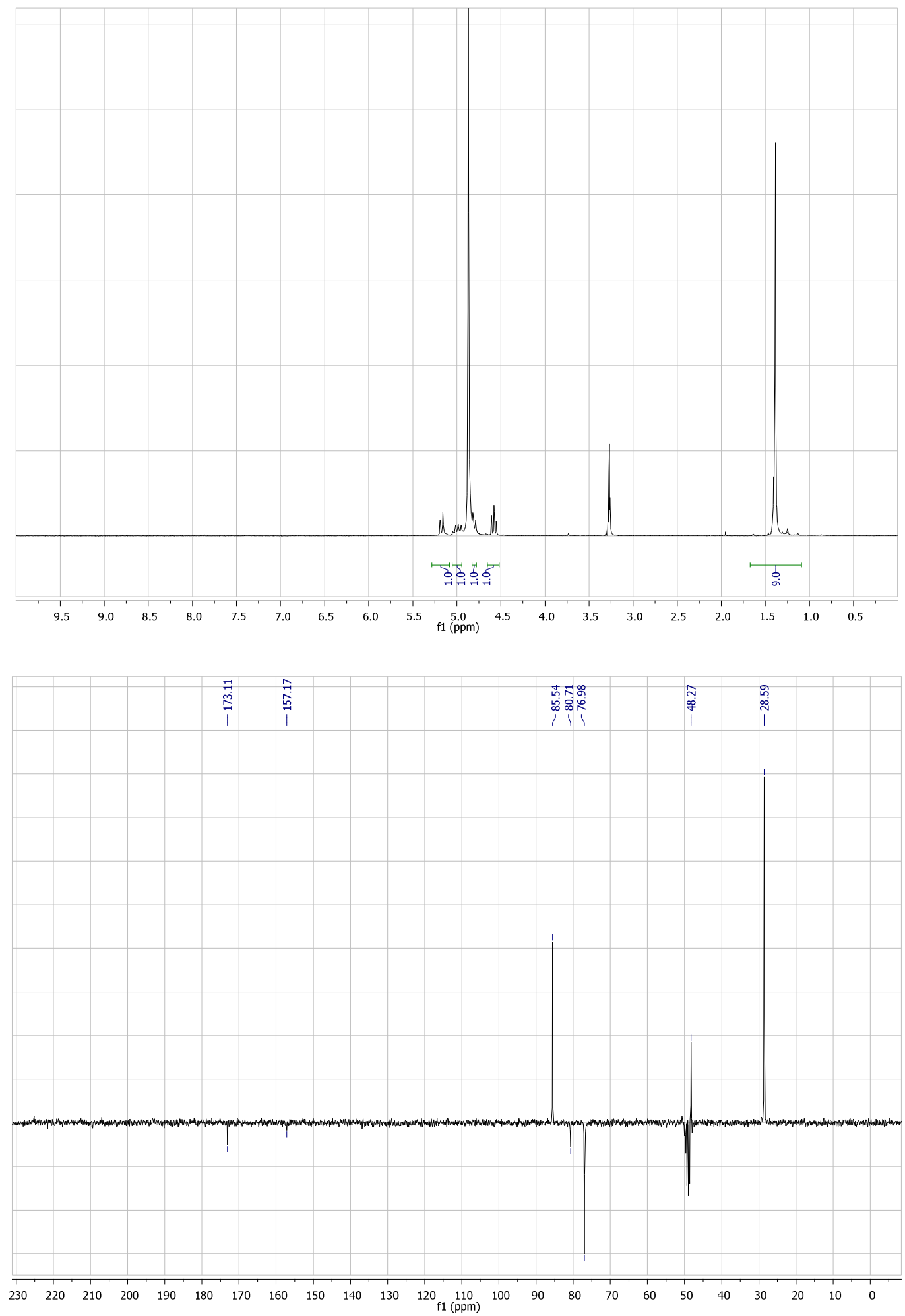
Racemic trans 3-((tert-butoxycarbonyl)amino)oxetane-2-carboxylic acid<smiles>CC(C)(C)OC(=O)N[C@H]1CO[C@H]1C(=O)O</smiles>

(士)-9b
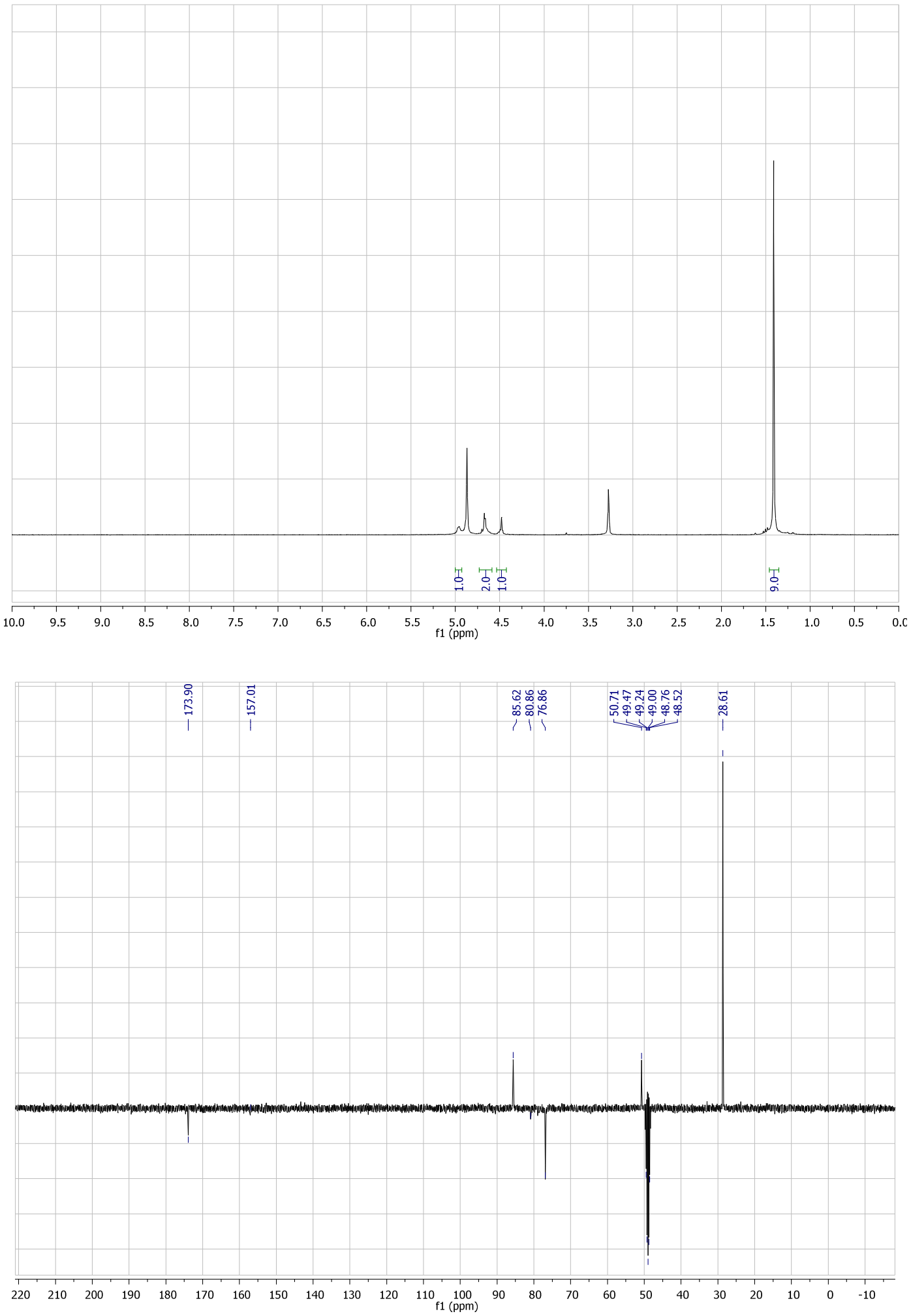
Racemic cis and trans butyl 3-((tert-butoxycarbonyl)amino)oxetane-2-carboxylate<smiles>CCCOC(=O)C1OCC1NC(=O)OCc1ccccc1</smiles>

$( \pm)-10 a$<smiles>CCCOC(=O)C1OCC1NC(=O)OCc1ccccc1</smiles>

$( \pm)-10 b$

Analyses were made on an unseparated and indistinguishable mixture of both 10a:10b=1:1
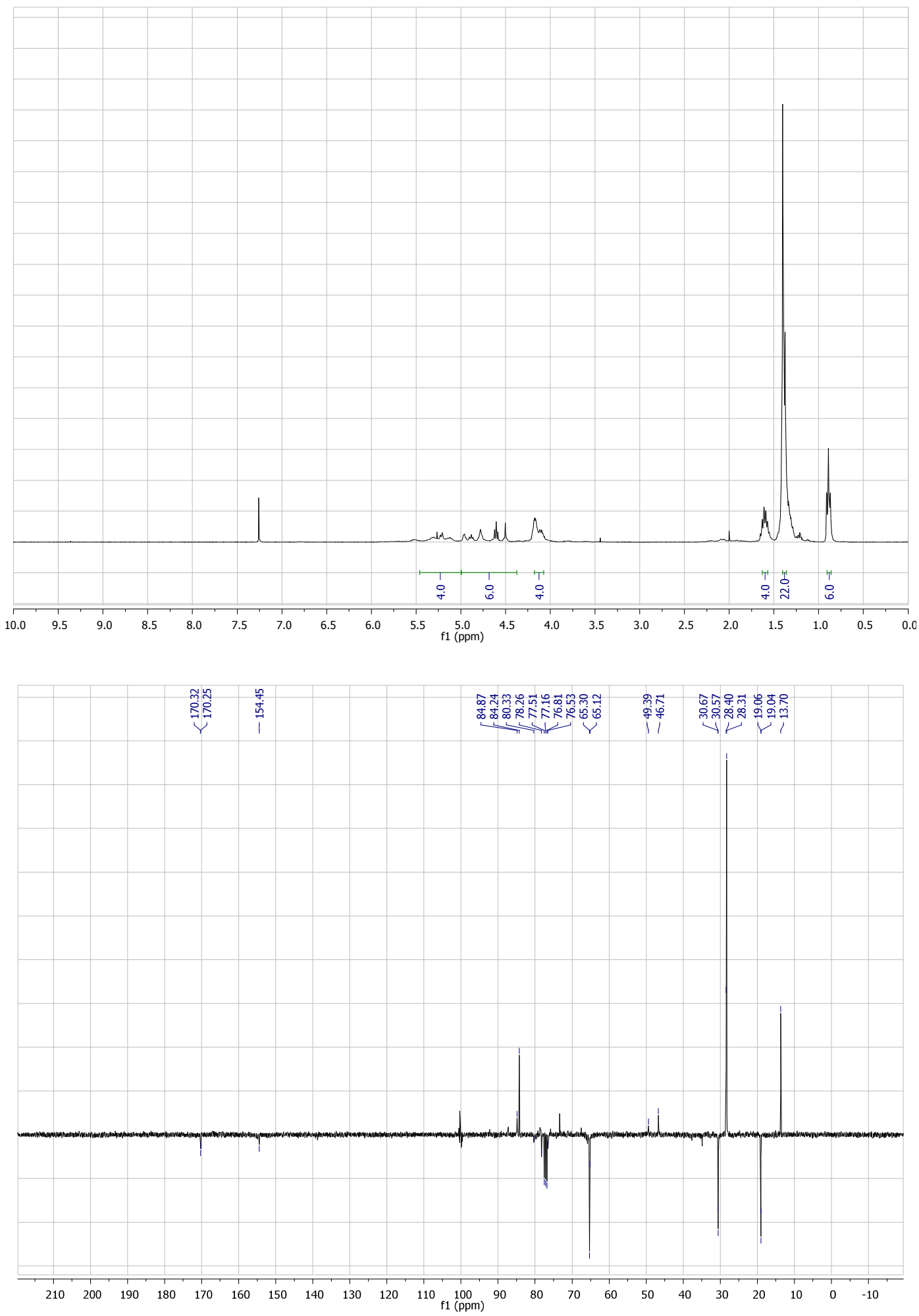
tert-butyl ((2R,3S)-2-((R)-2-0xo-4-phenyloxazolidine-3-carbonyl)oxetan-3-yl)carbamate<smiles>O=C(N[C@H]1COC1C(=O)N1C(=O)OC[C@H]1c1ccccc1)Oc1ccccc1</smiles>
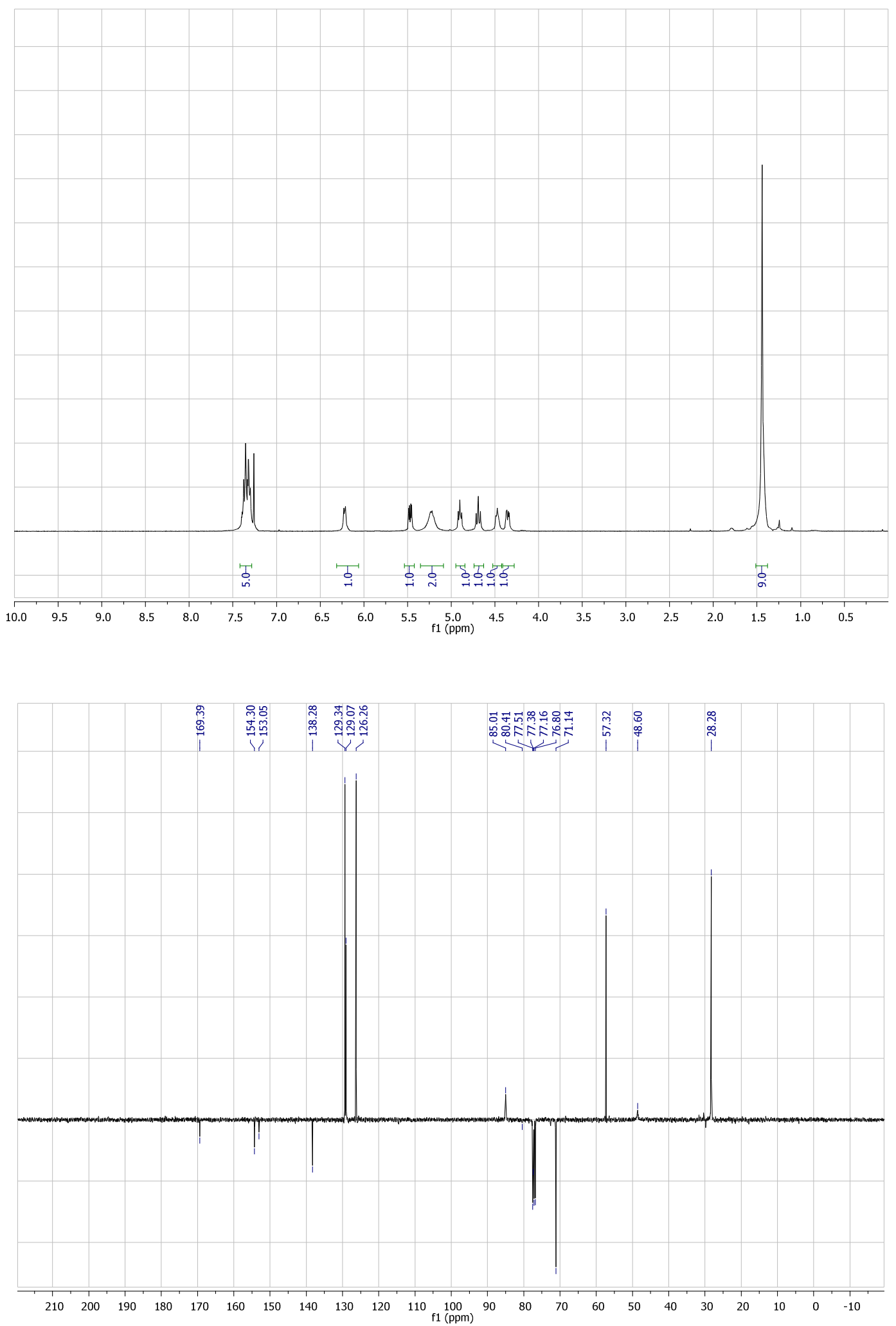
tert-butyl ((2S,3R)-2-((R)-2-0xo-4-phenyloxazolidine-3-carbonyl)oxetan-3-yl)carbamate
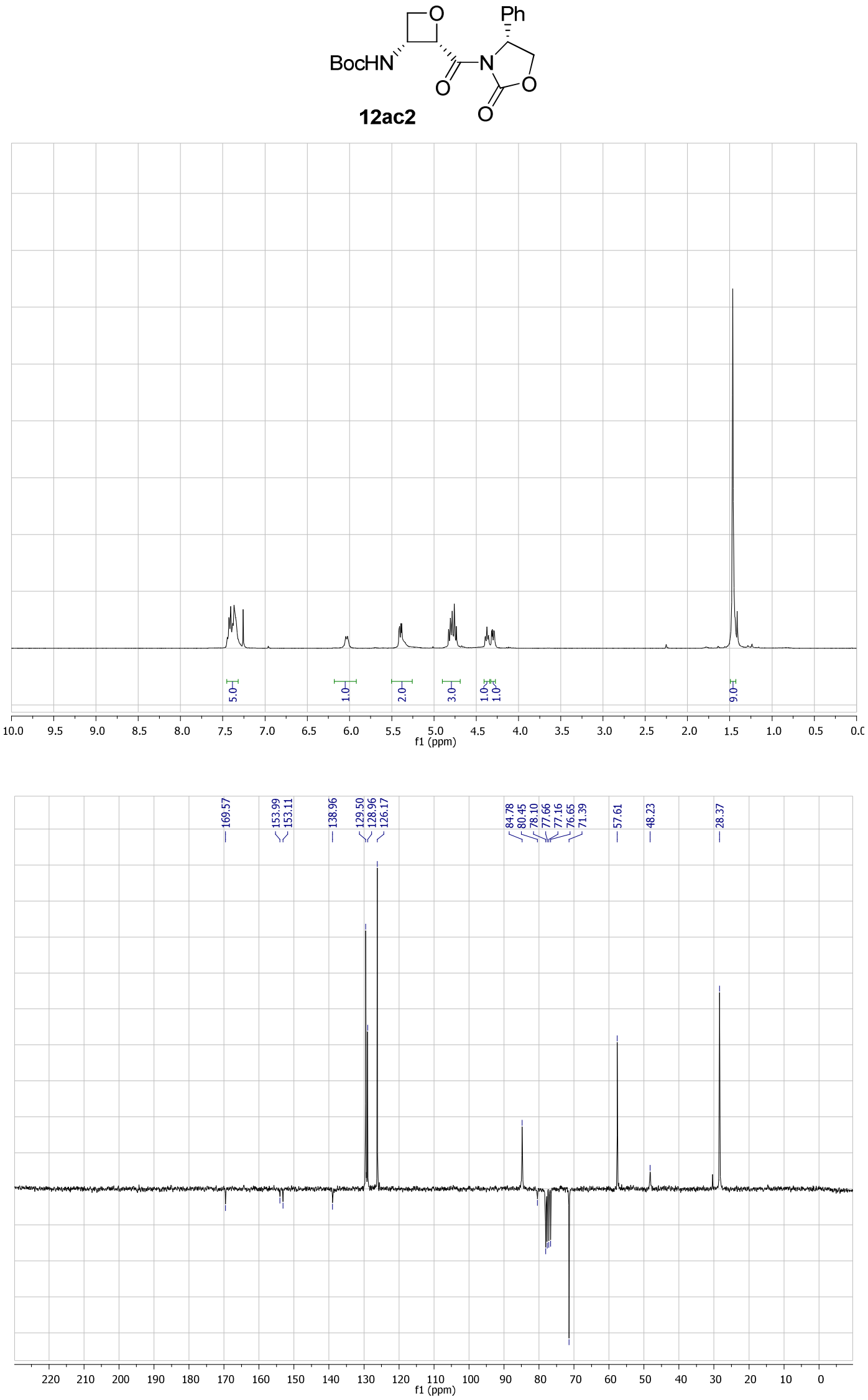


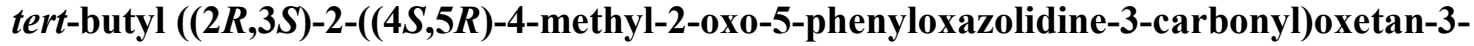
yl)carbamate
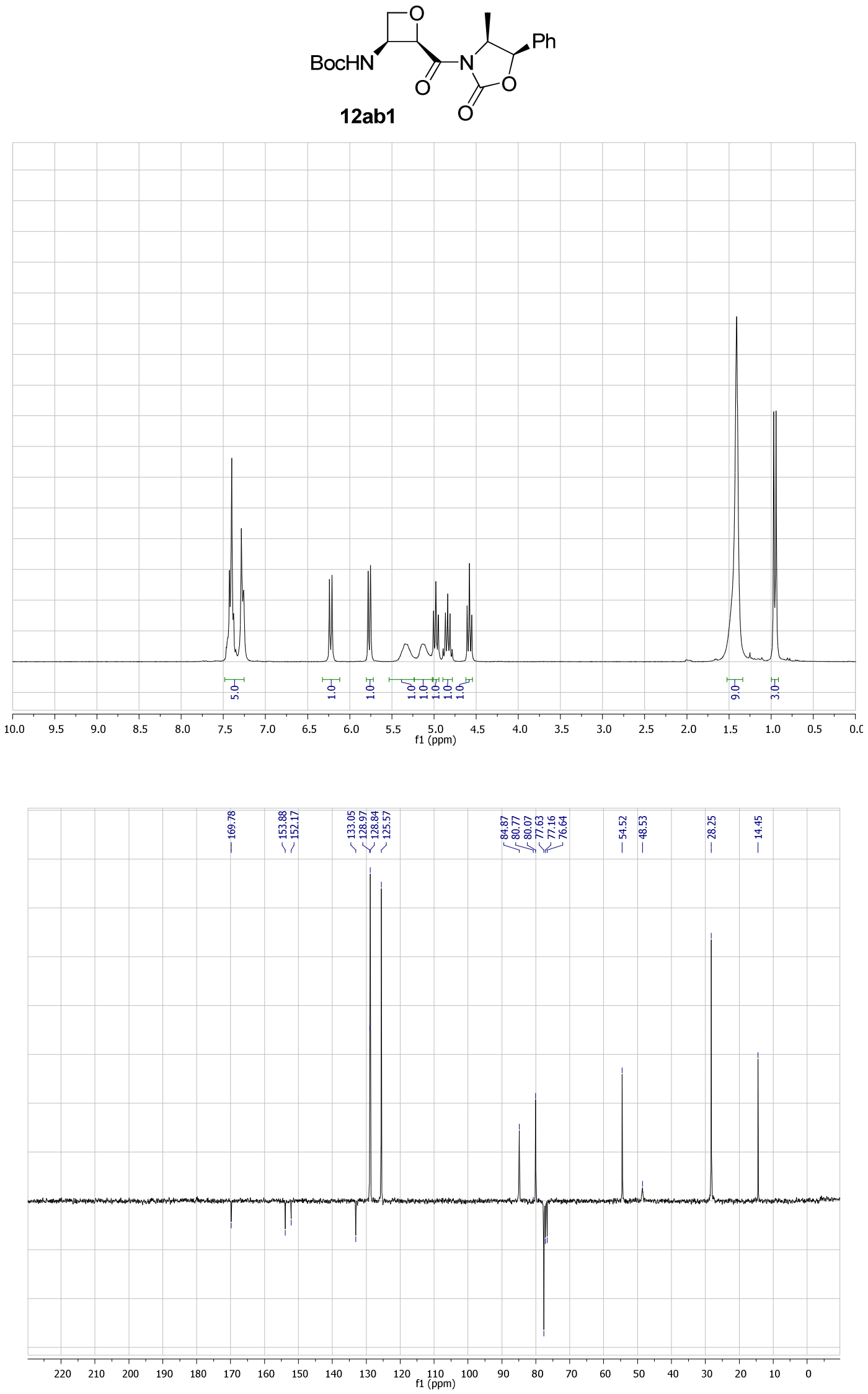
tert-butyl((2S,3R)-2-((4S,5R)-4-methyl-2-oxo-5-phenyloxazolidine-3-carbonyl)oxetan-3yl)carbamate.
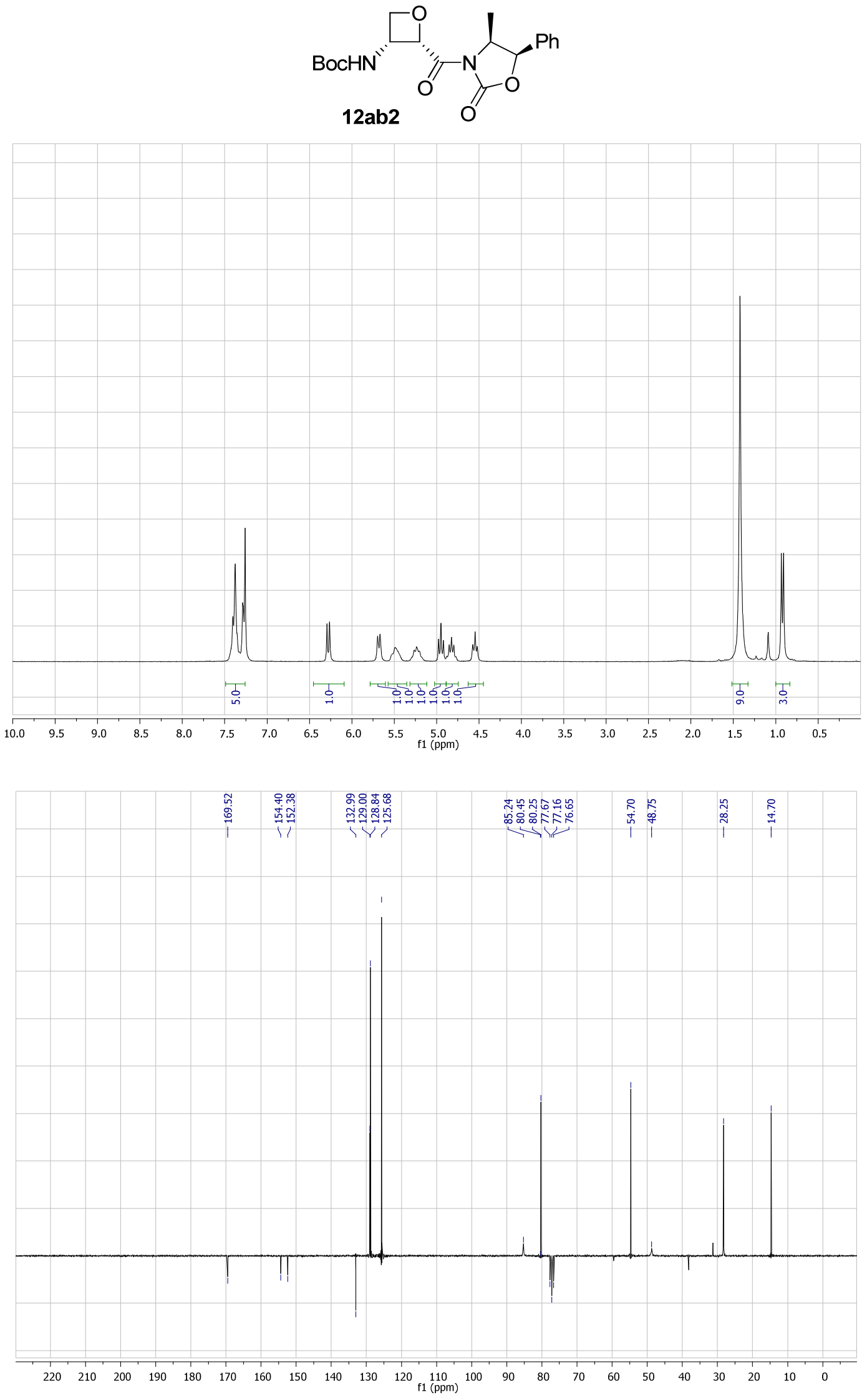
tert-butyl ((2R,3R)-2-((S)-4-((benzyloxy)methyl)-2-oxooxazolidine-3-carbonyl)oxetan-3yl)carbamate
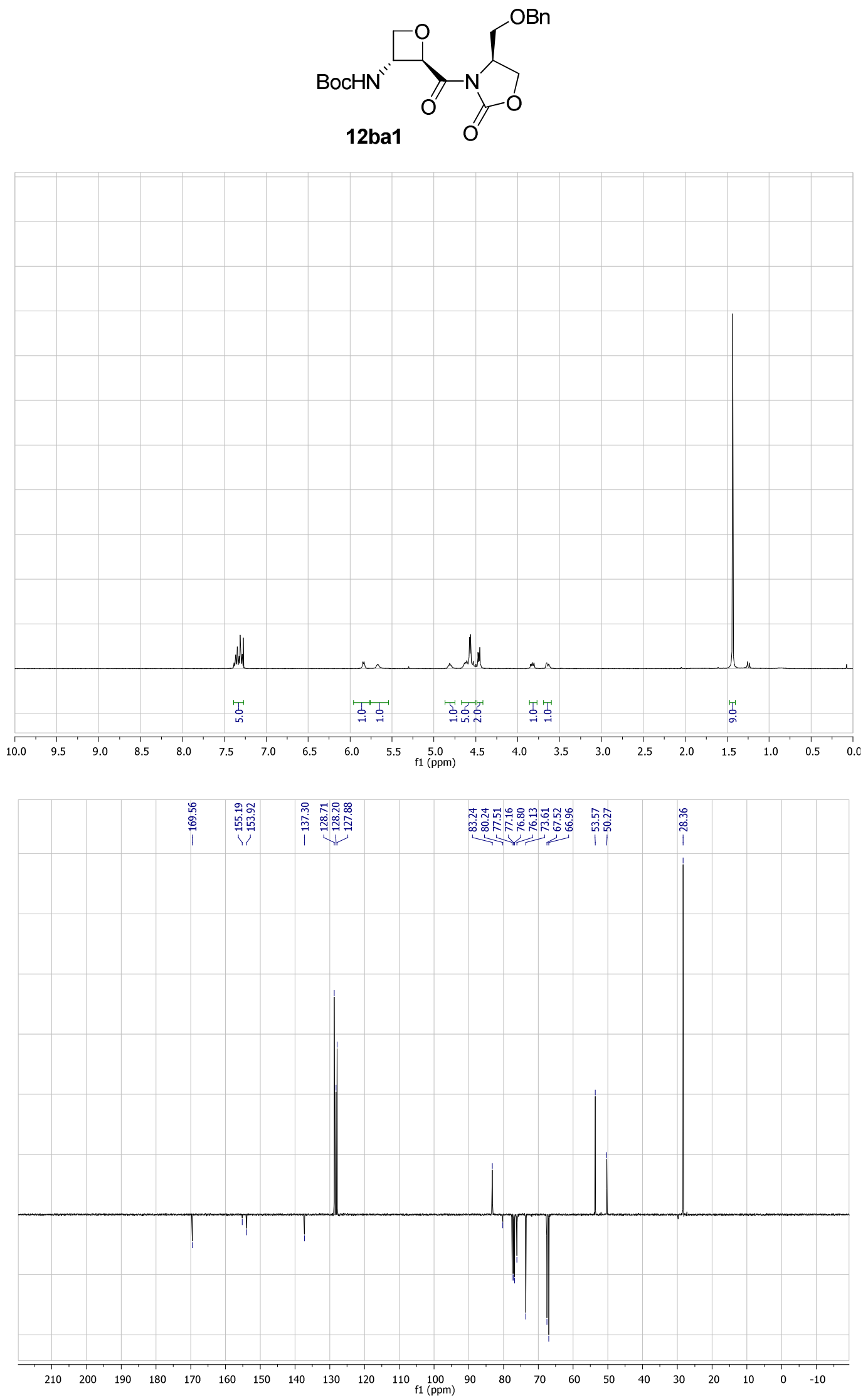
tert-butyl ((2S,3S)-2-((S)-4-((benzyloxy)methyl)-2-oxooxazolidine-3-carbonyl)oxetan-3yl)carbamate
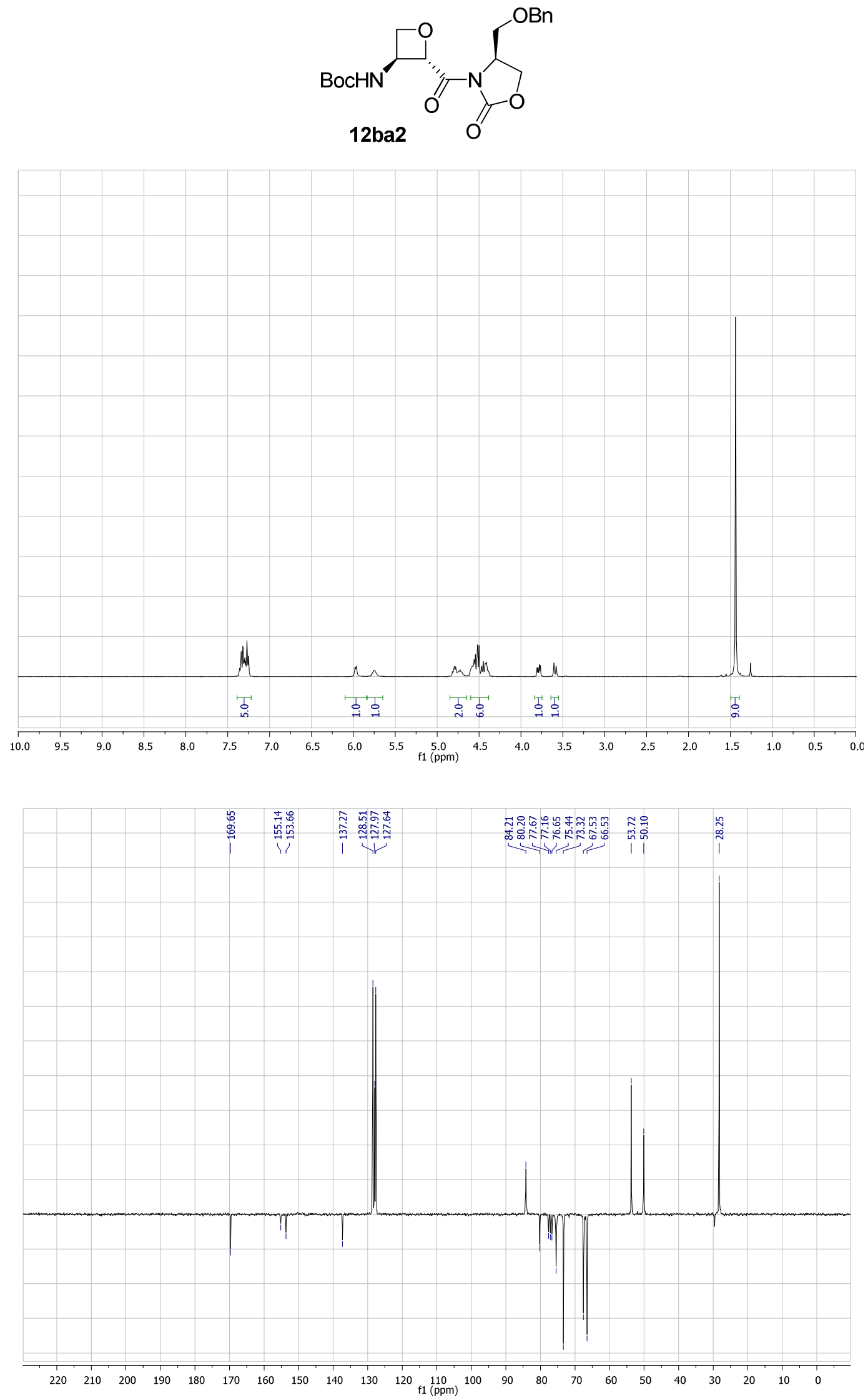
tert-butyl ((2R,3R)-2-((4S,5R)-4-methyl-2-oxo-5-phenyloxazolidine-3-carbonyl)oxetan-3yl)carbamate

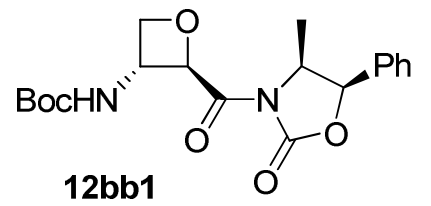

Analyses were made on an unseparated mixture of both 12bb1:12bb2=1:2.4
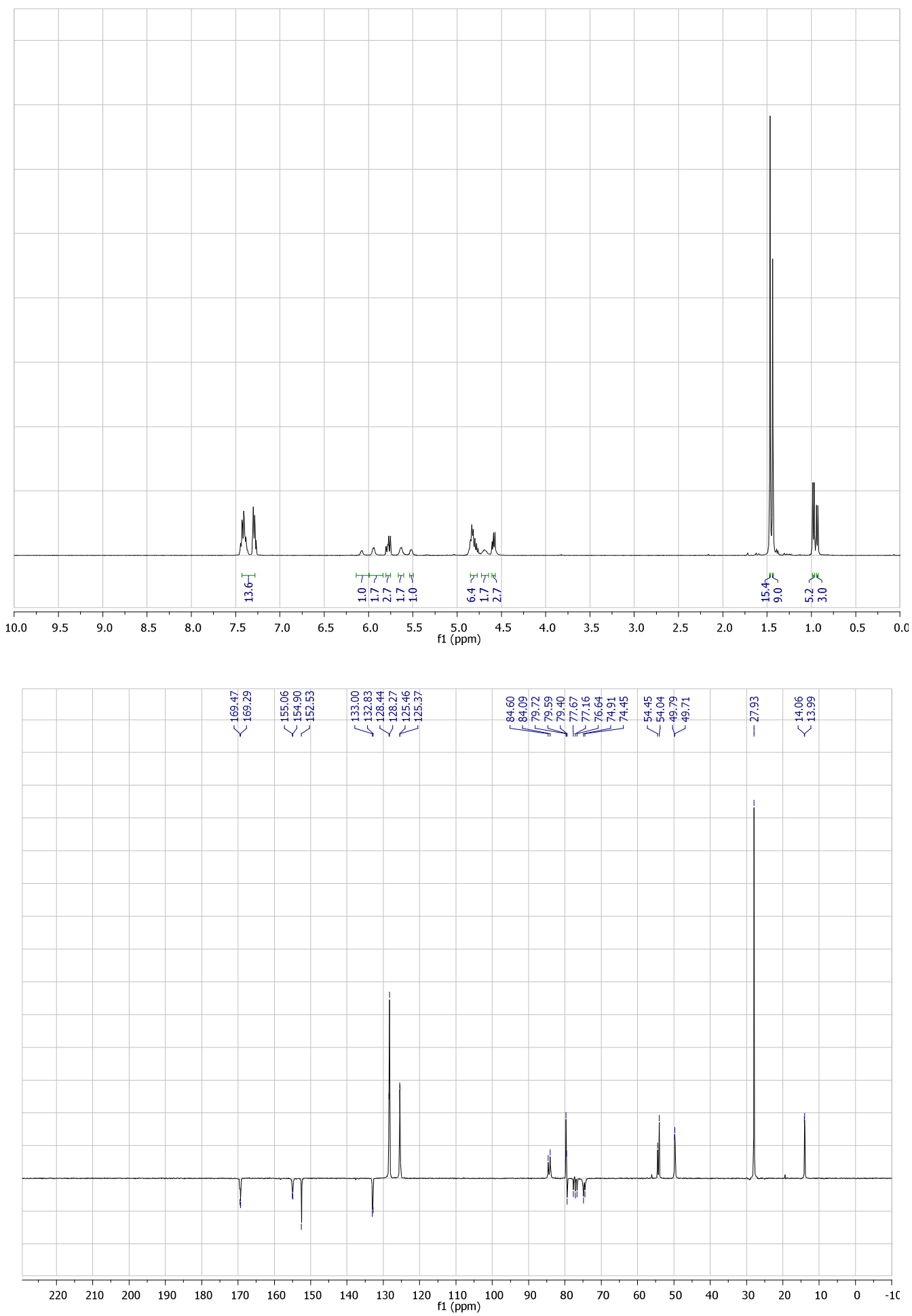
tert-butyl ((2S,3S)-2-((4S,5R)-4-methyl-2-0xo-5-phenyloxazolidine-3-carbonyl)oxetan-3yl)carbamate
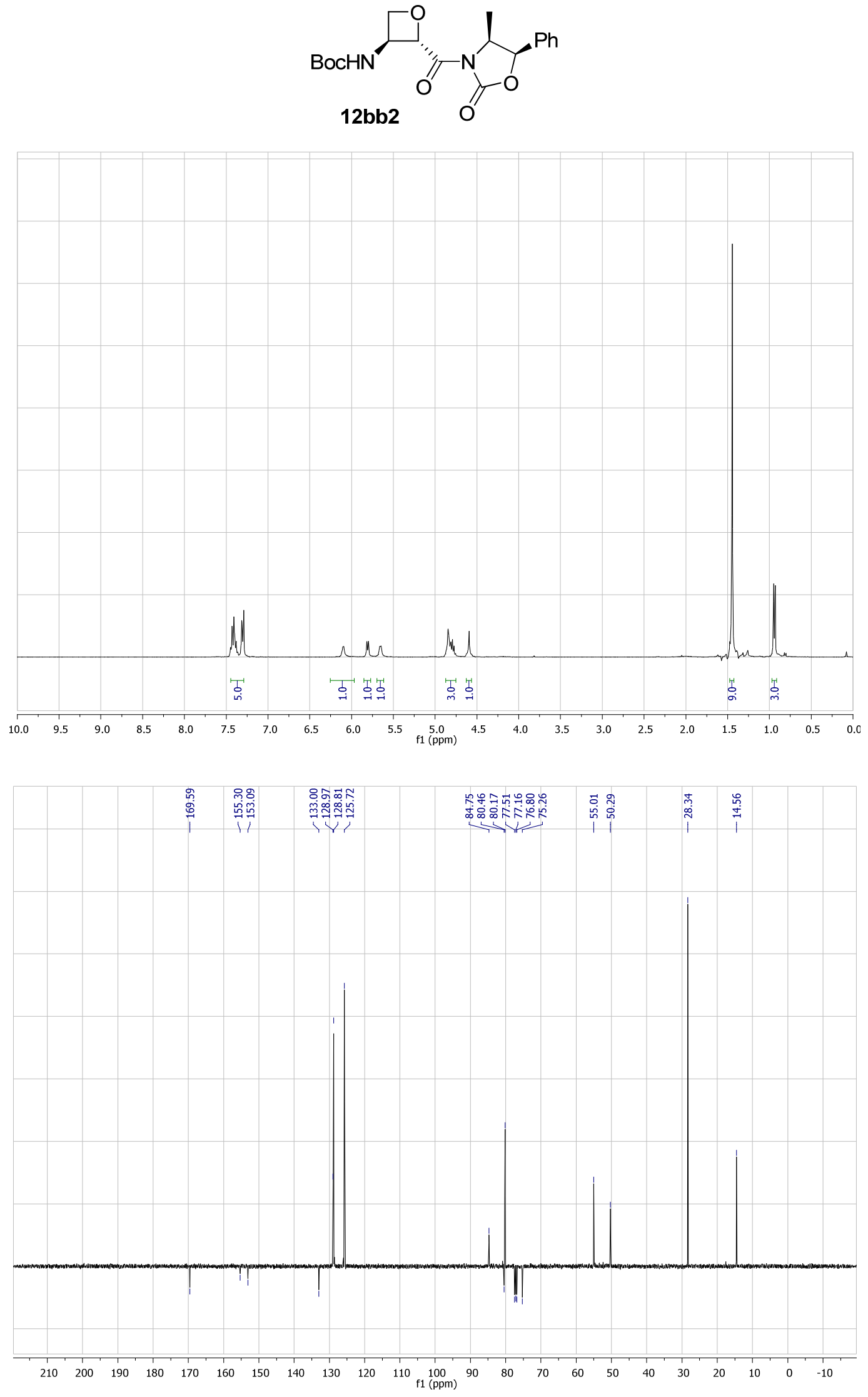
(2R,3S)-3-((tert-butoxycarbonyl)amino)oxetane-2-carboxylic acid (prepared according to Scheme 4 from 12ac1)
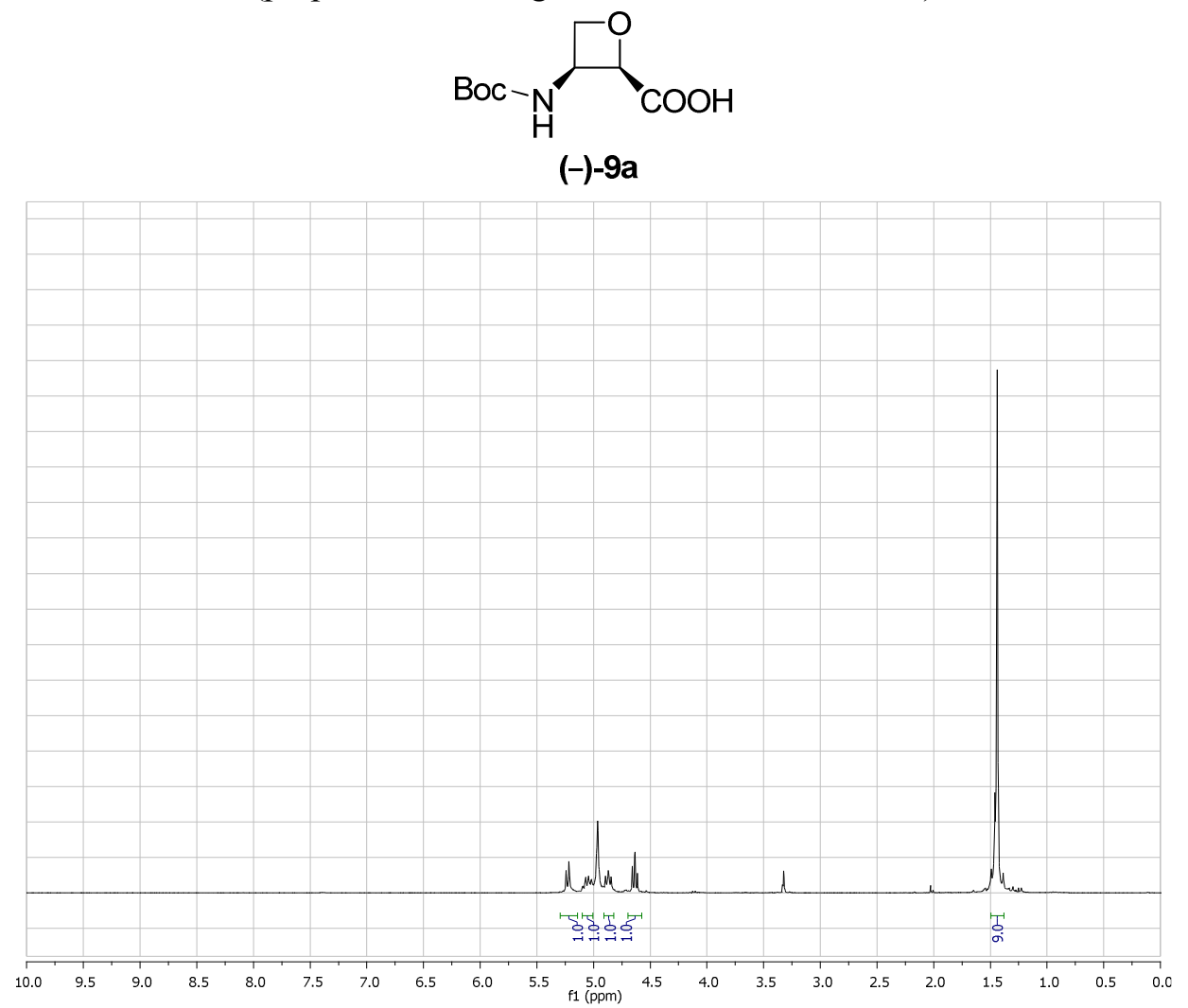

(2S,3R)-3-((tert-butoxycarbonyl)amino)oxetane-2-carboxylic acid (prepared according to Scheme 4 from 12ac2)<smiles>CC(C)(C)OC(=O)N[C@@H]1CO[C@@H]1C(=O)O</smiles>

$(+)-9 a$

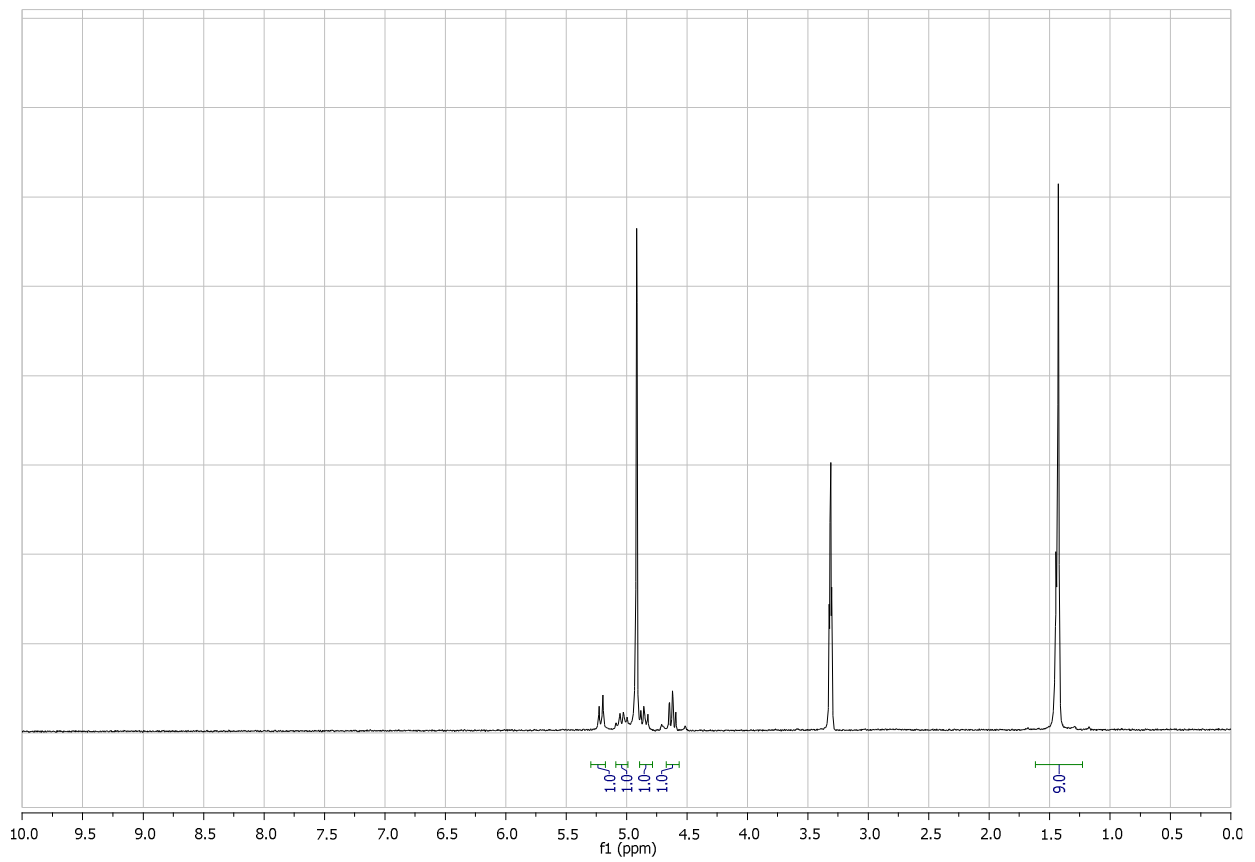


(2S,3R)-3-((tert-butoxycarbonyl)amino)oxetane-2-carboxylic acid (prepared according to Scheme 4 from 12ab2)

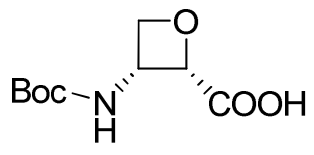

$(+)-9 a$

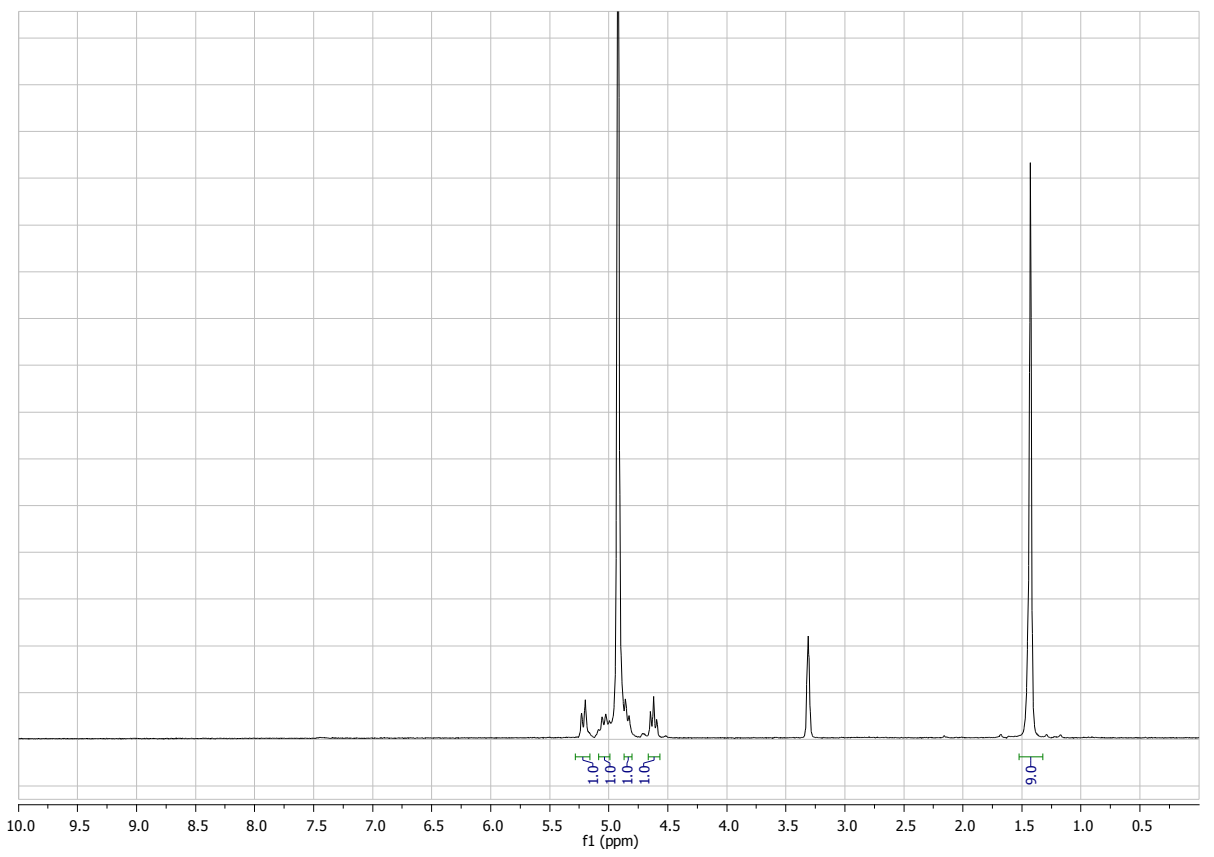

(2R,3R)-3-((tert-butoxycarbonyl)amino)oxetane-2-carboxylic acid (prepared according to Scheme 4 from 12ba1)<smiles>CC(C)(C)OC(=O)N[C@@H]1COC1C(=O)O</smiles>

$(+)-9 b$

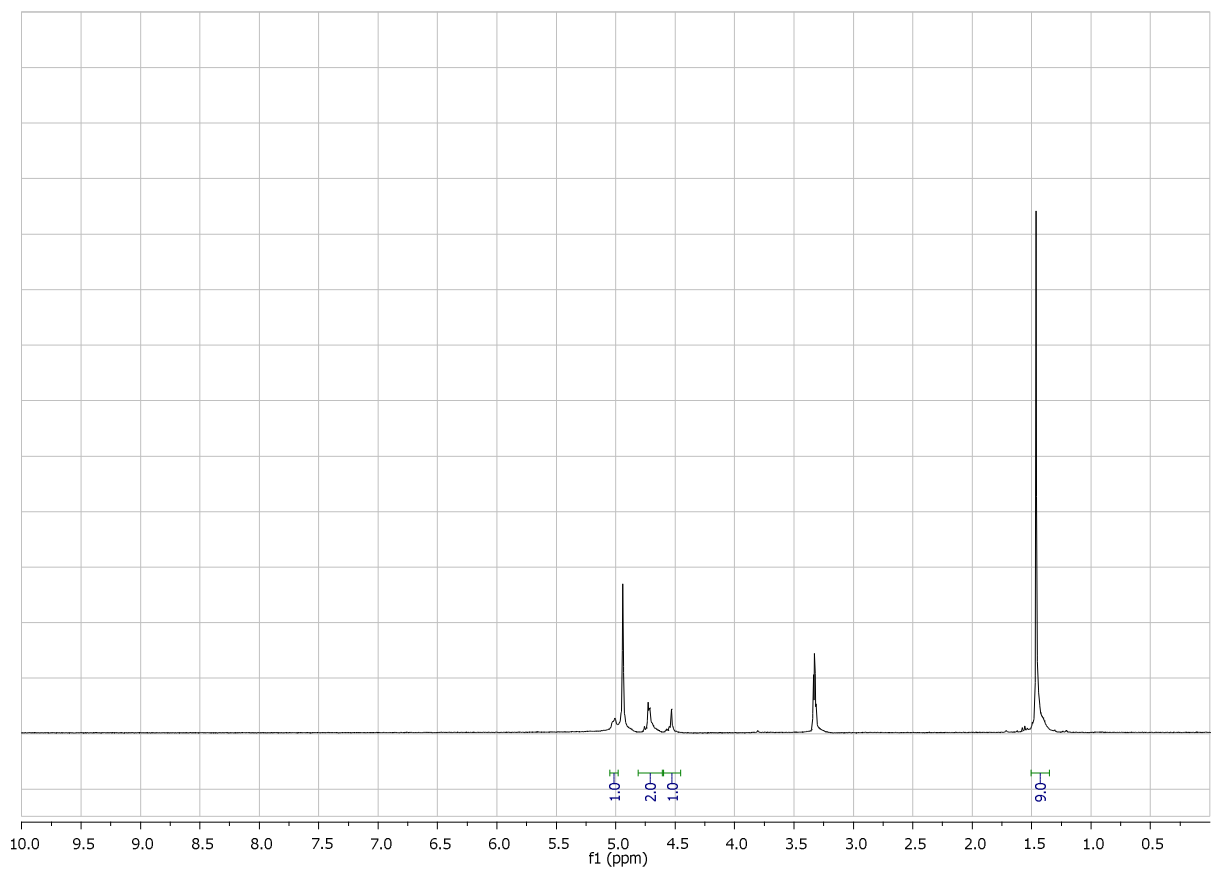


(2S,3S)-3-((tert-butoxycarbonyl)amino)oxetane-2-carboxylic acid (prepared according to Scheme 4 from 12ba2)<smiles>O=C(O)OC(=O)NC1CO[C@@H]1C(=O)O</smiles>

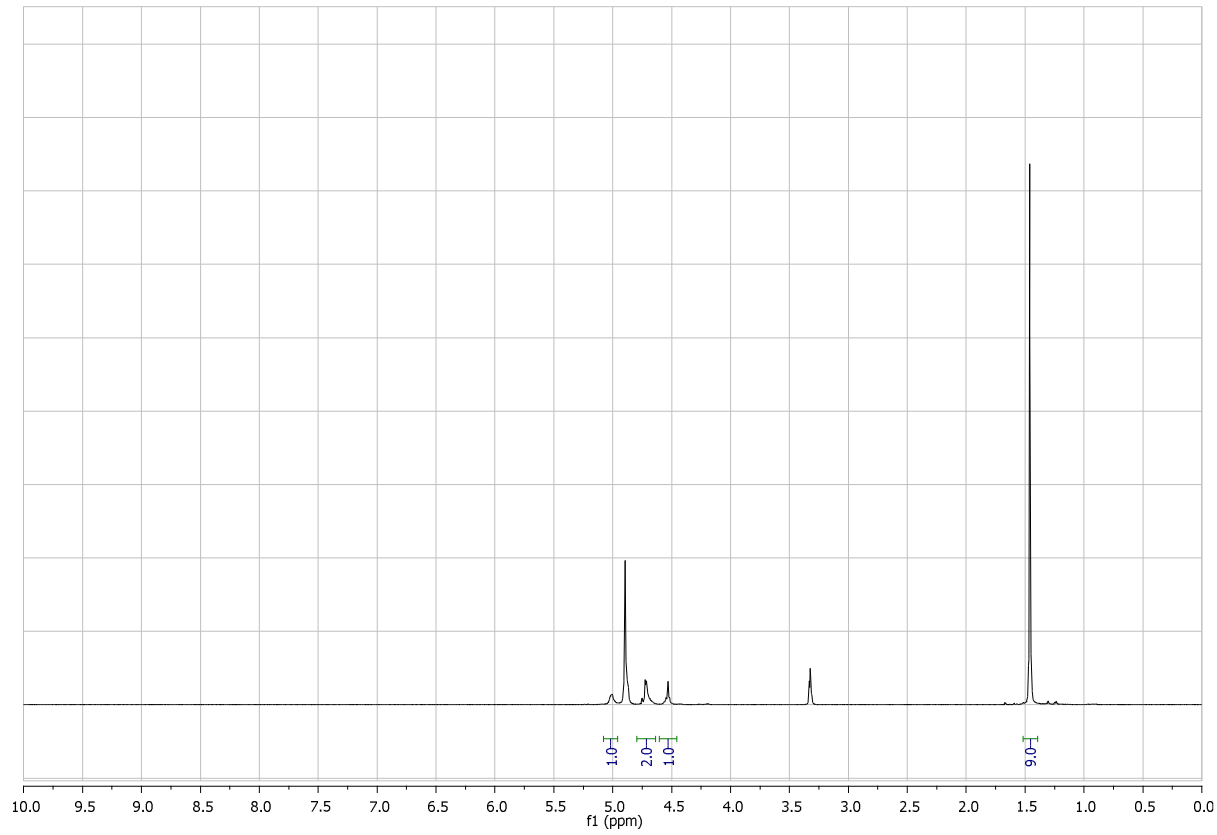

(2S,3S)-3-((tert-butoxycarbonyl)amino)oxetane-2-carboxylic acid (prepared according to Scheme 4 from 12bb2)<smiles>O=C(O)OC(=O)NC1CO[C@@H]1C(=O)O</smiles>

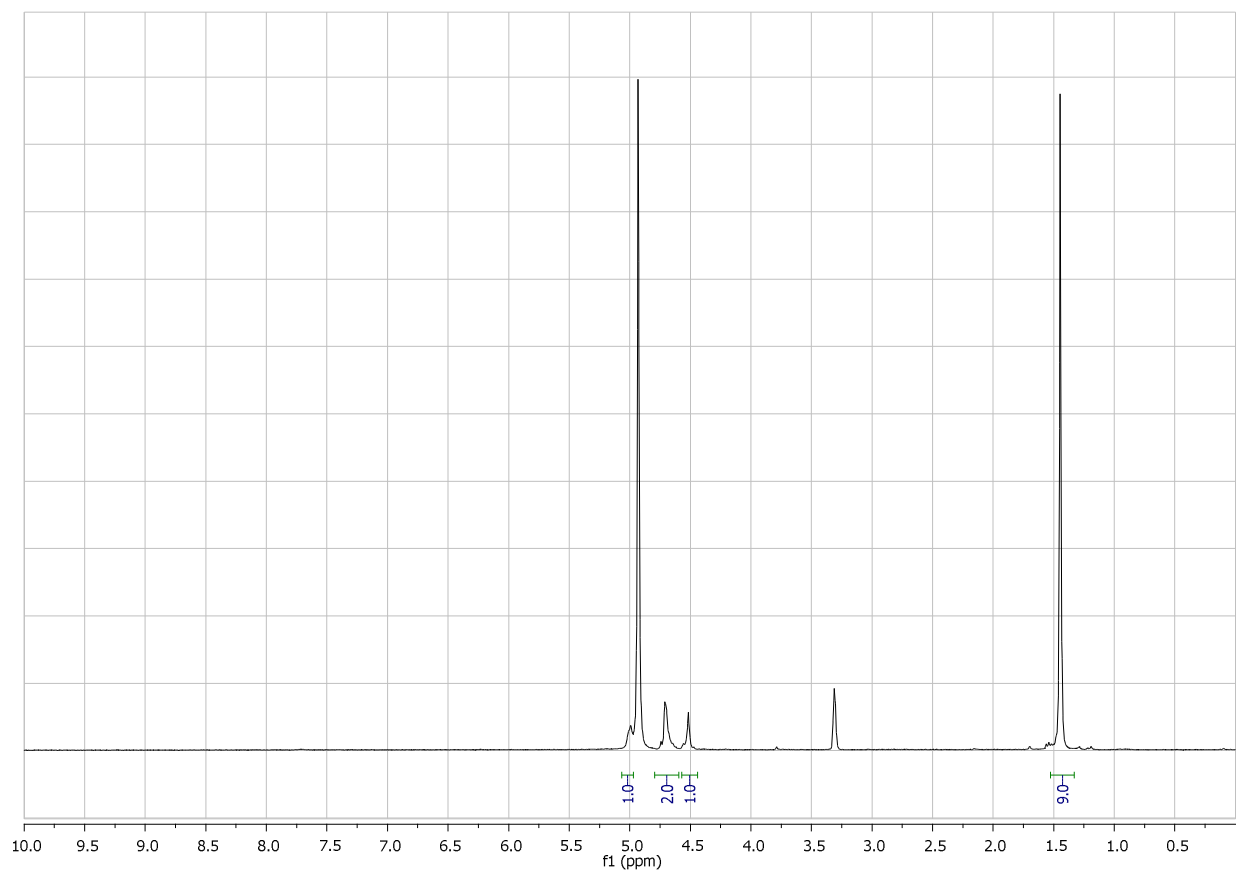




\section{(2R,3S)-3-aminooxetane-2-carboxylic acid}
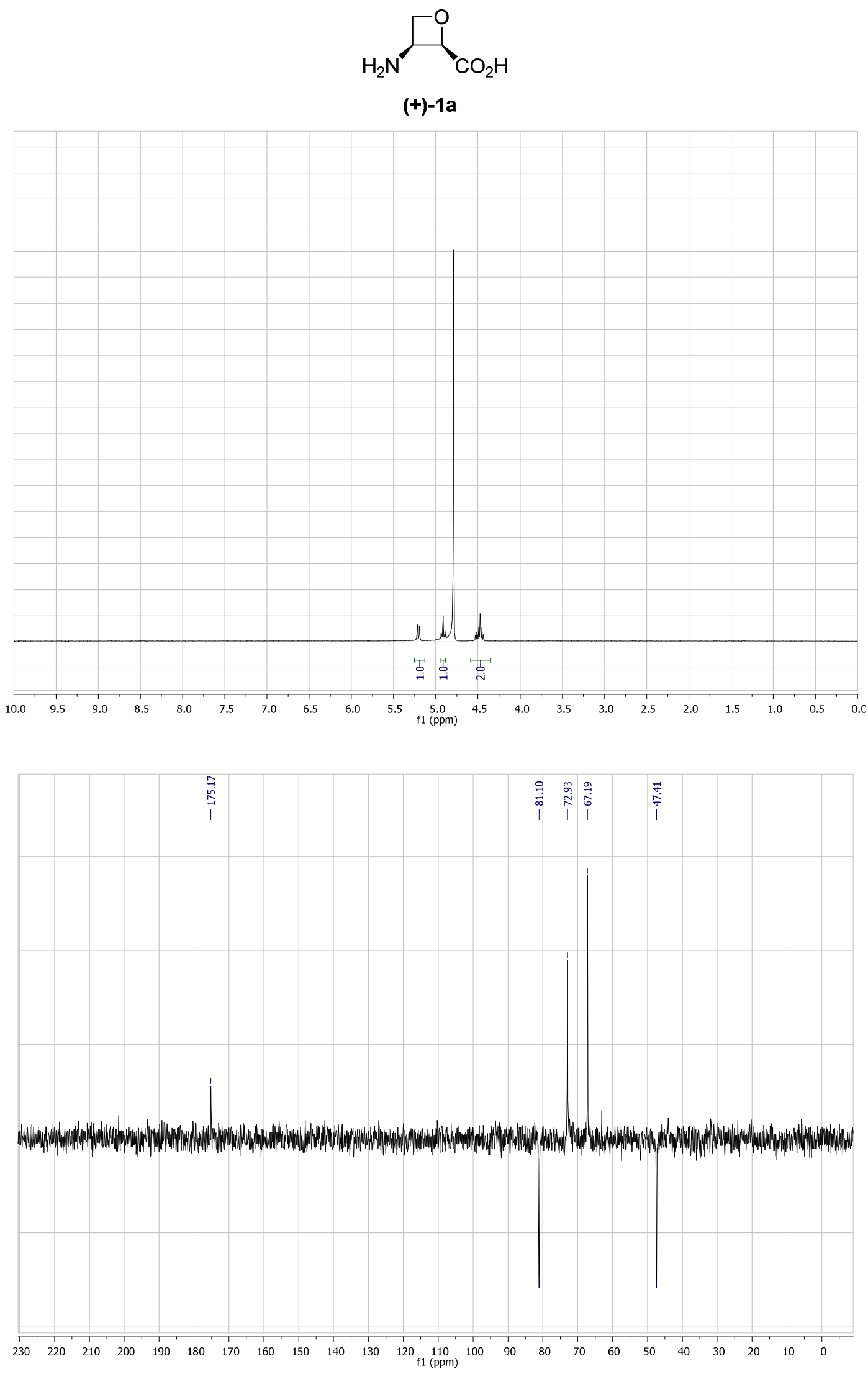
(2S,3R)-3-aminooxetane-2-carboxylic acid
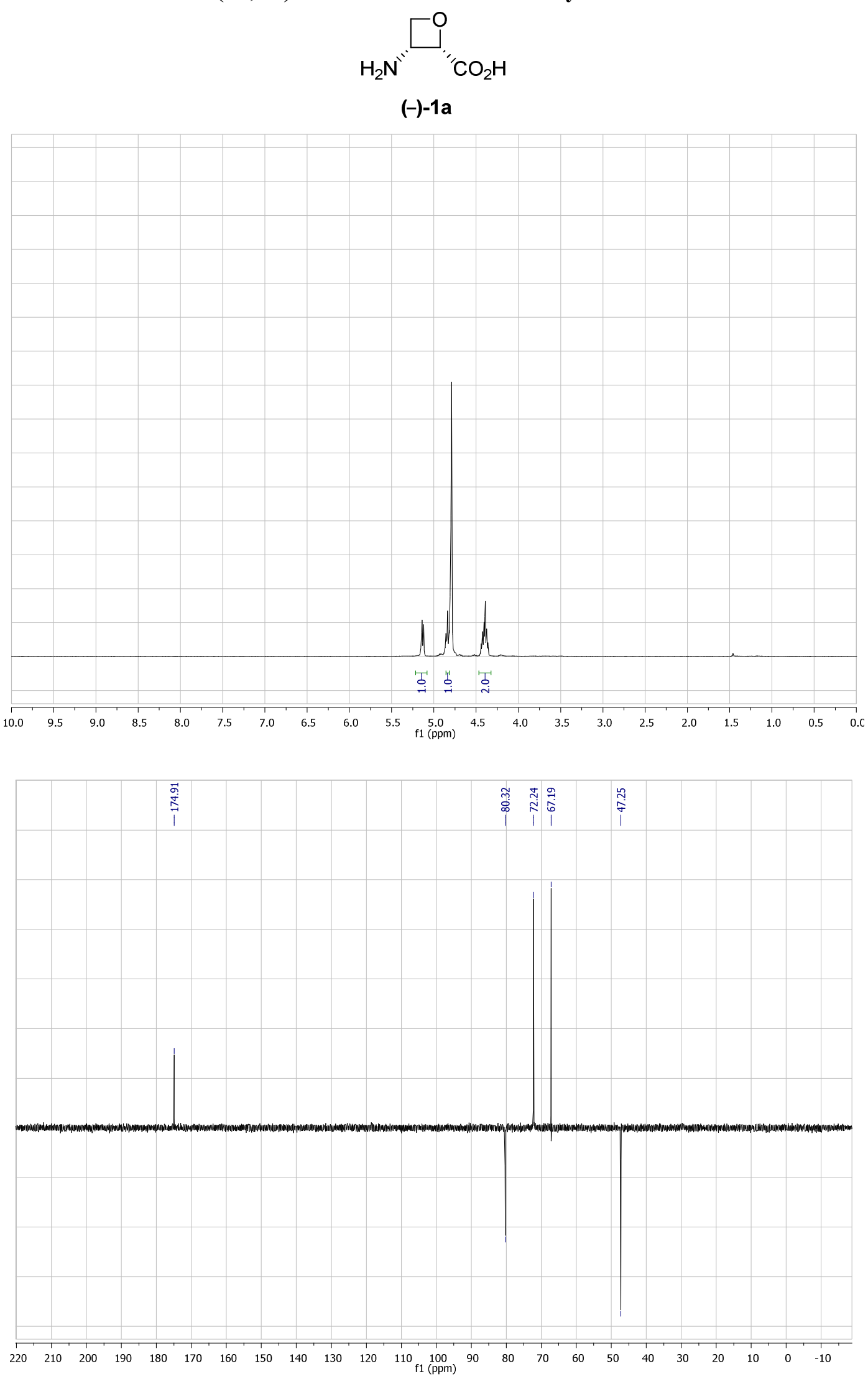
(2R,3R)-3-aminooxetane-2-carboxylic acid
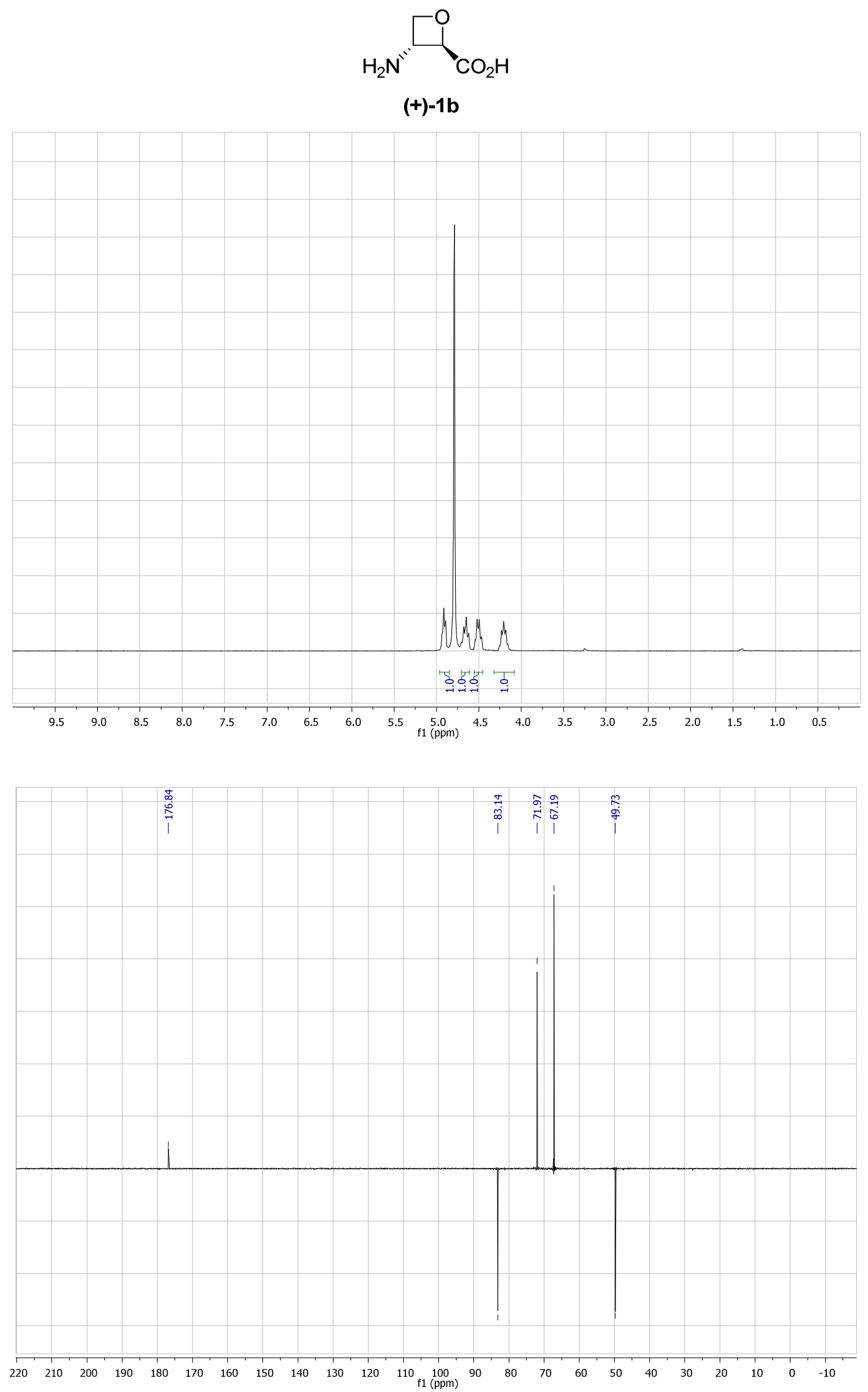
(2S,3S)-3-aminooxetane-2-carboxylic acid

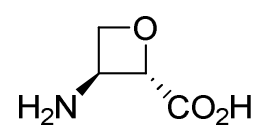

$(-)-1 b$
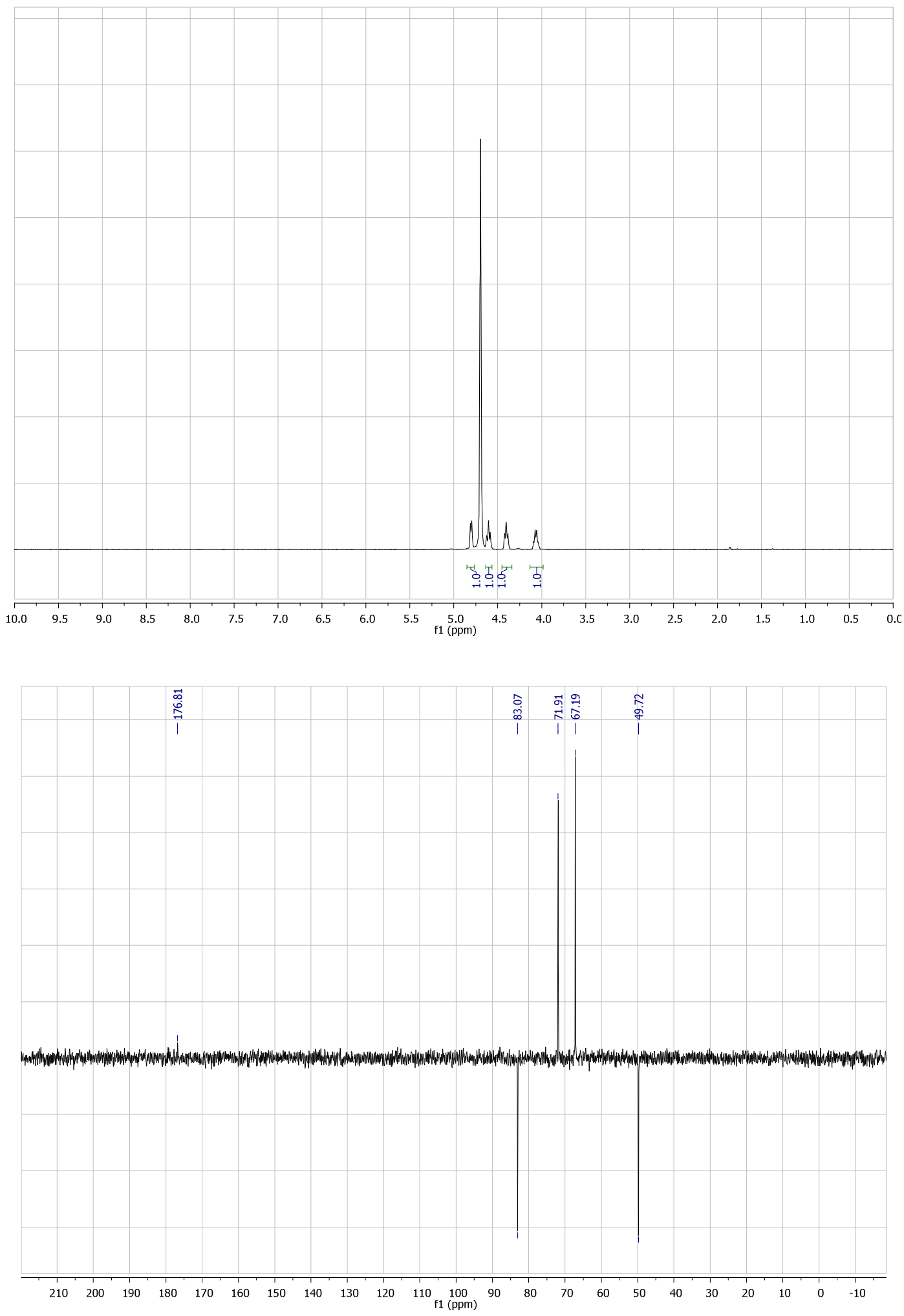
(2R,3S)-butyl 3-(N-(tert-butoxycarbonyl)formamido)oxetane-2-carboxylate (prepared according to Scheme 5)<smiles>CCOC(=O)C1OCC1N(C=O)C(=O)OCc1ccccc1</smiles>

$(-)-8 \mathbf{a}$

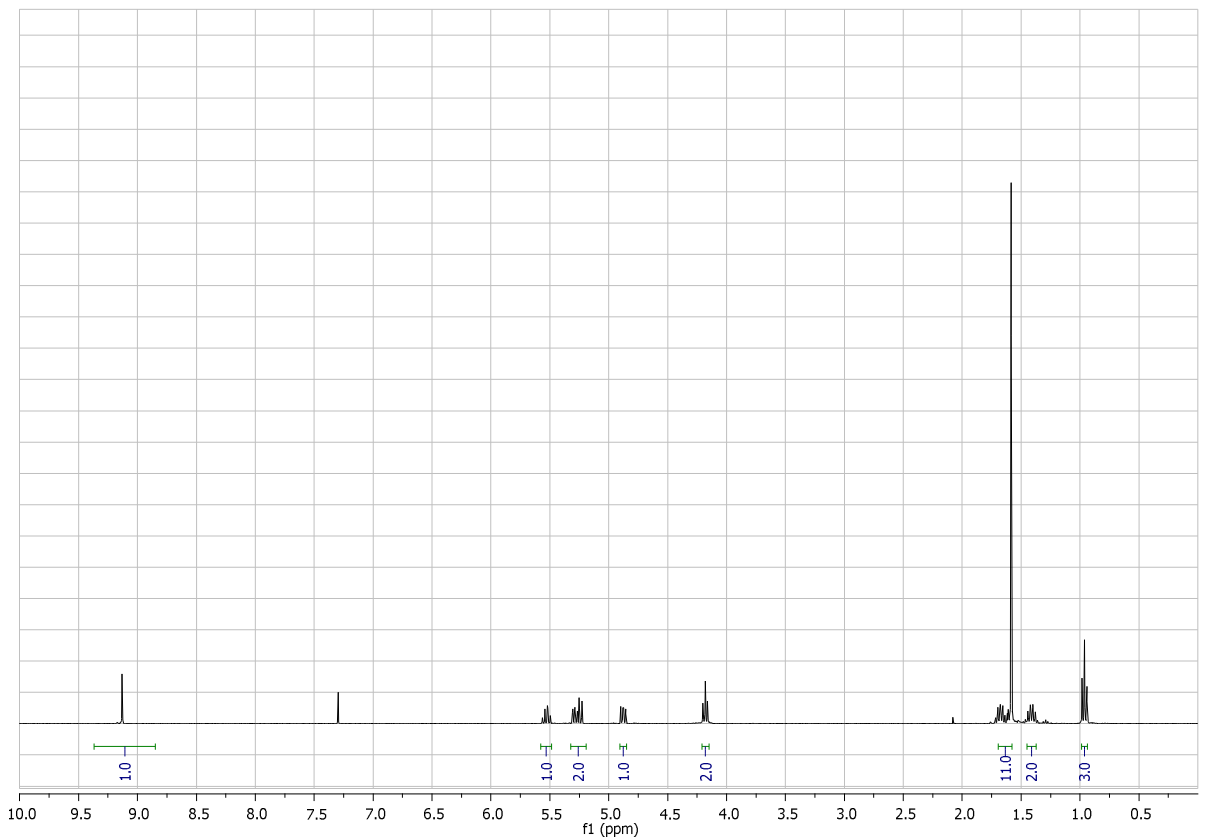

(2S,3R)-butyl 3-(N-(tert-butoxycarbonyl)formamido)oxetane-2-carboxylate (prepared according to Scheme 5)

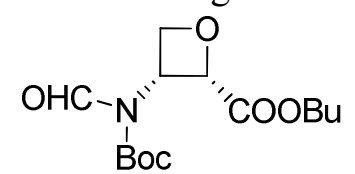

$(+)-8 a$

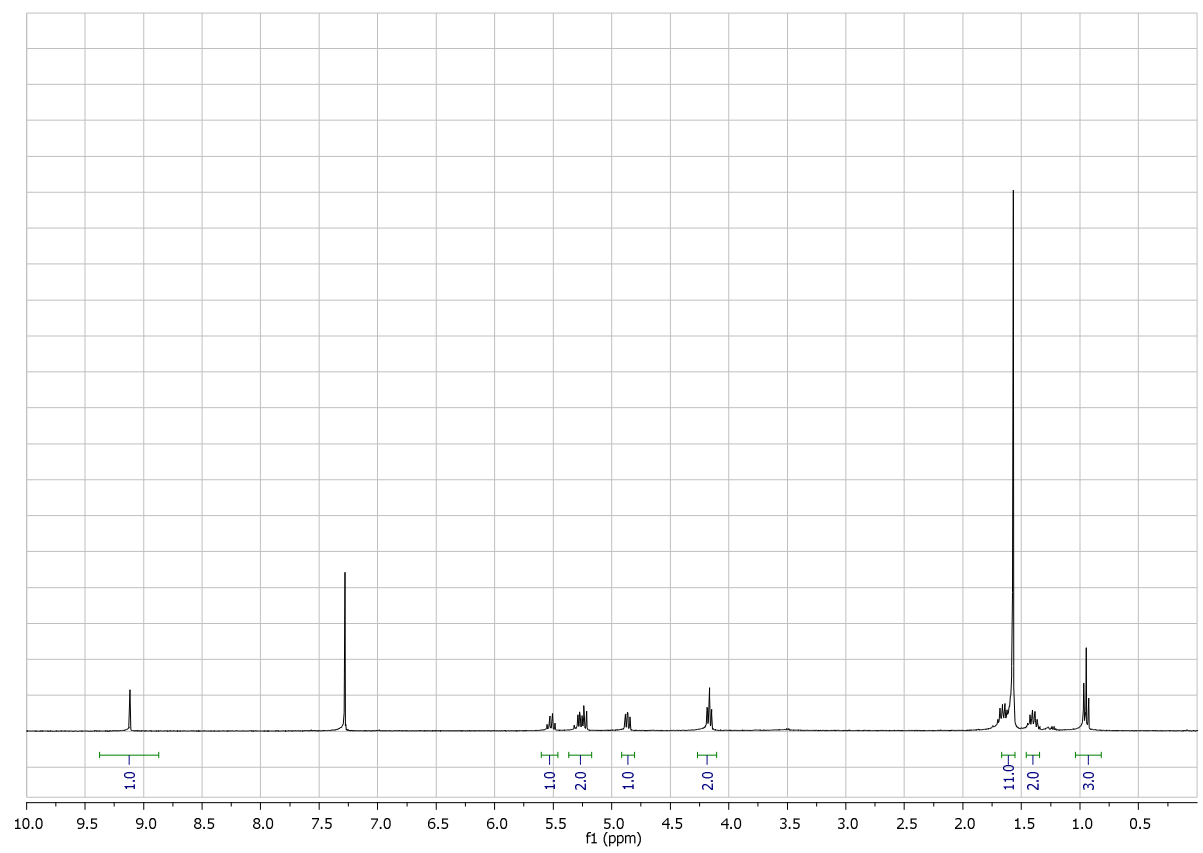


(2R,3R)-butyl 3-(N-(tert-butoxycarbonyl)formamido)oxetane-2-carboxylate (prepared according to Scheme 5)

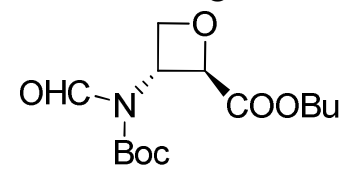

$(-)-8 b$

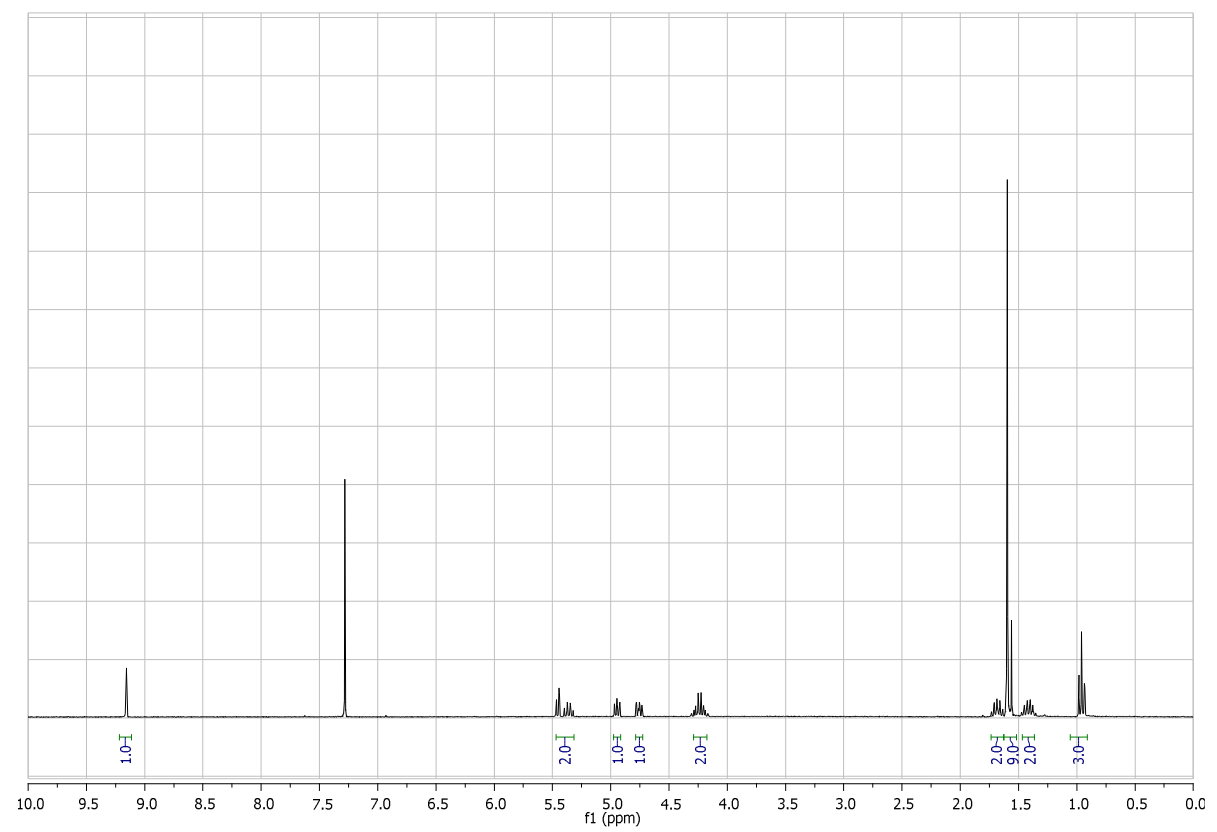

(2S,3S)-butyl 3-(N-(tert-butoxycarbonyl)formamido)oxetane-2-carboxylate (prepared according to Scheme 5)<smiles>CCOC(=O)[C@H]1OC[C@H]1N(C=O)C(=O)OCc1ccccc1</smiles>

$(+)-8 b$

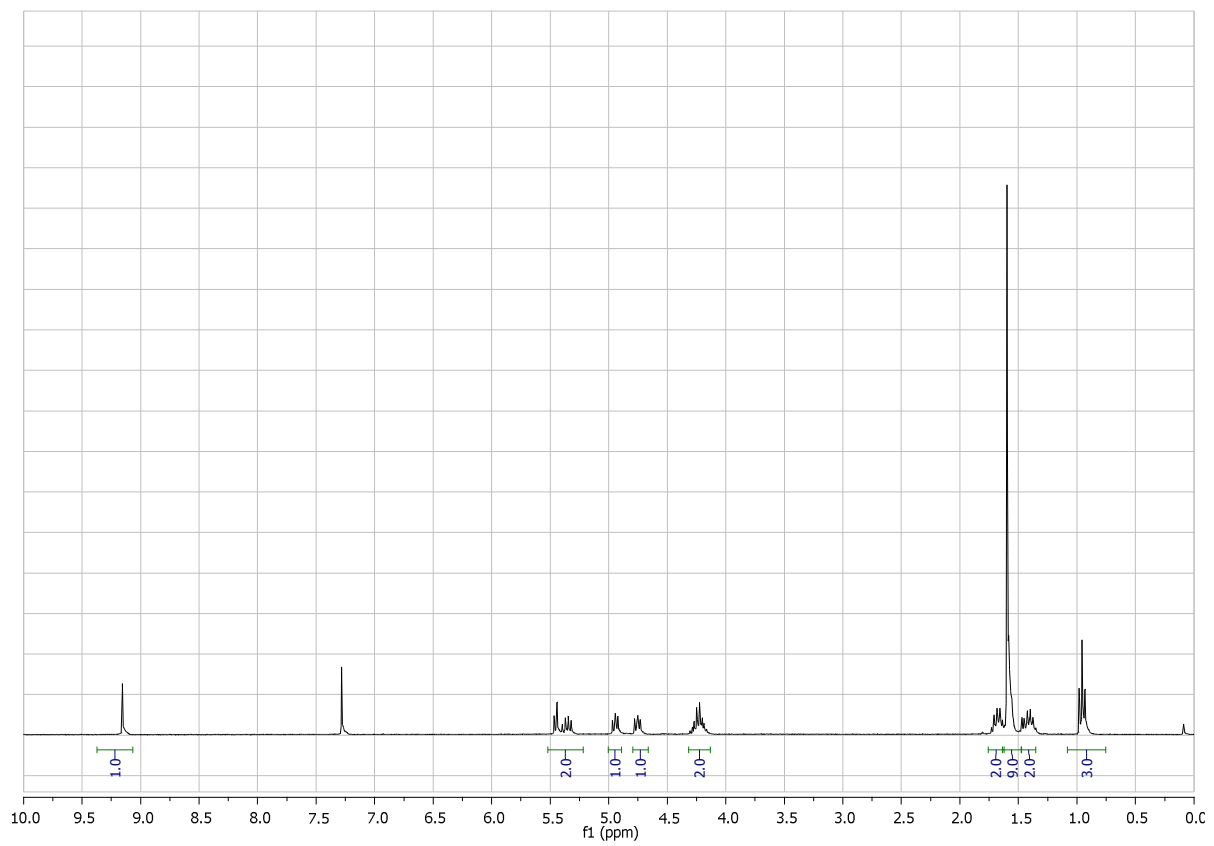


(2R,3S)-3-((tert-butoxycarbonyl)amino)oxetane-2-carboxylic acid (prepared according to Scheme 5)<smiles>O=C(O)OC(=O)N[C@H]1COC1C(=O)O</smiles>

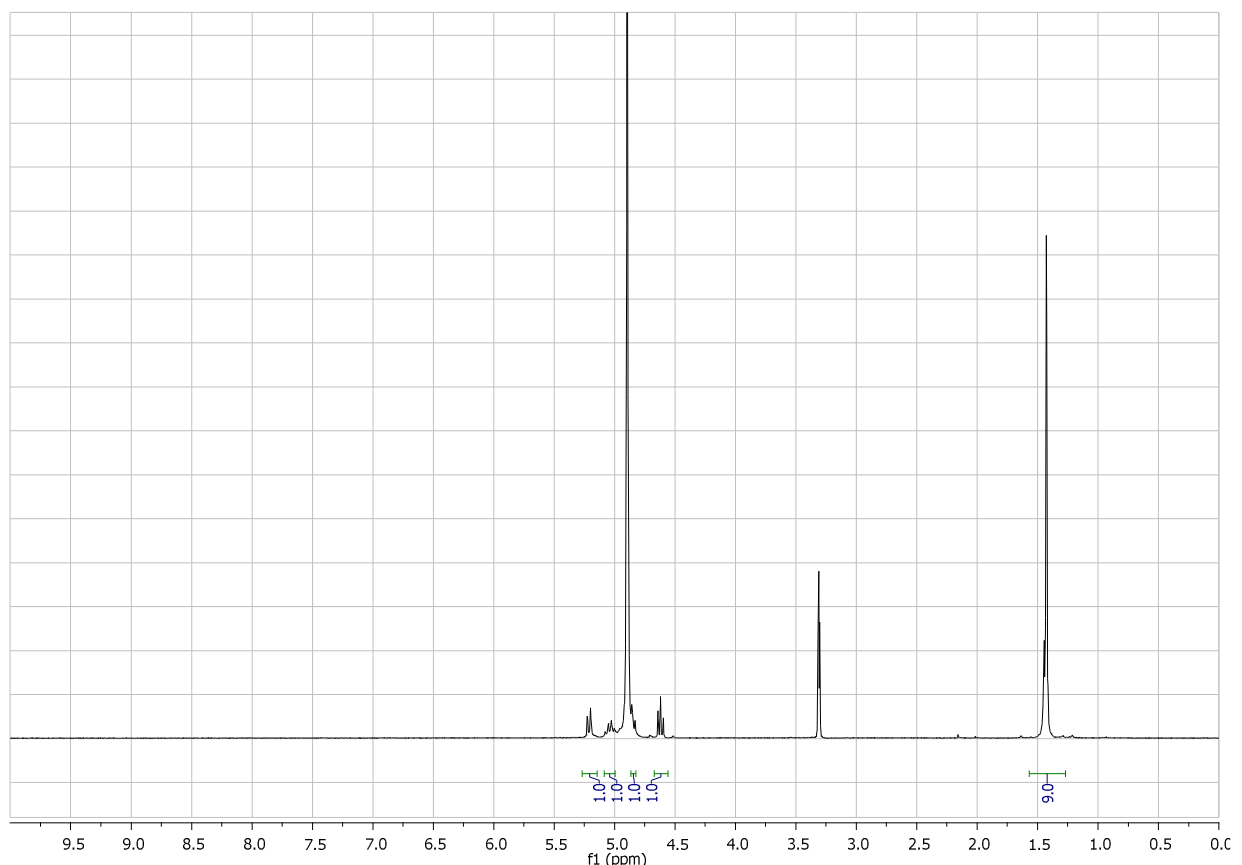

(2S,3R)-3-((tert-butoxycarbonyl)amino)oxetane-2-carboxylic acid (prepared according to Scheme 5)

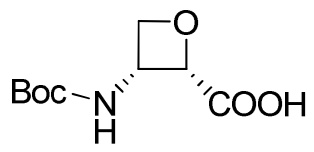

$(+)-9 a$

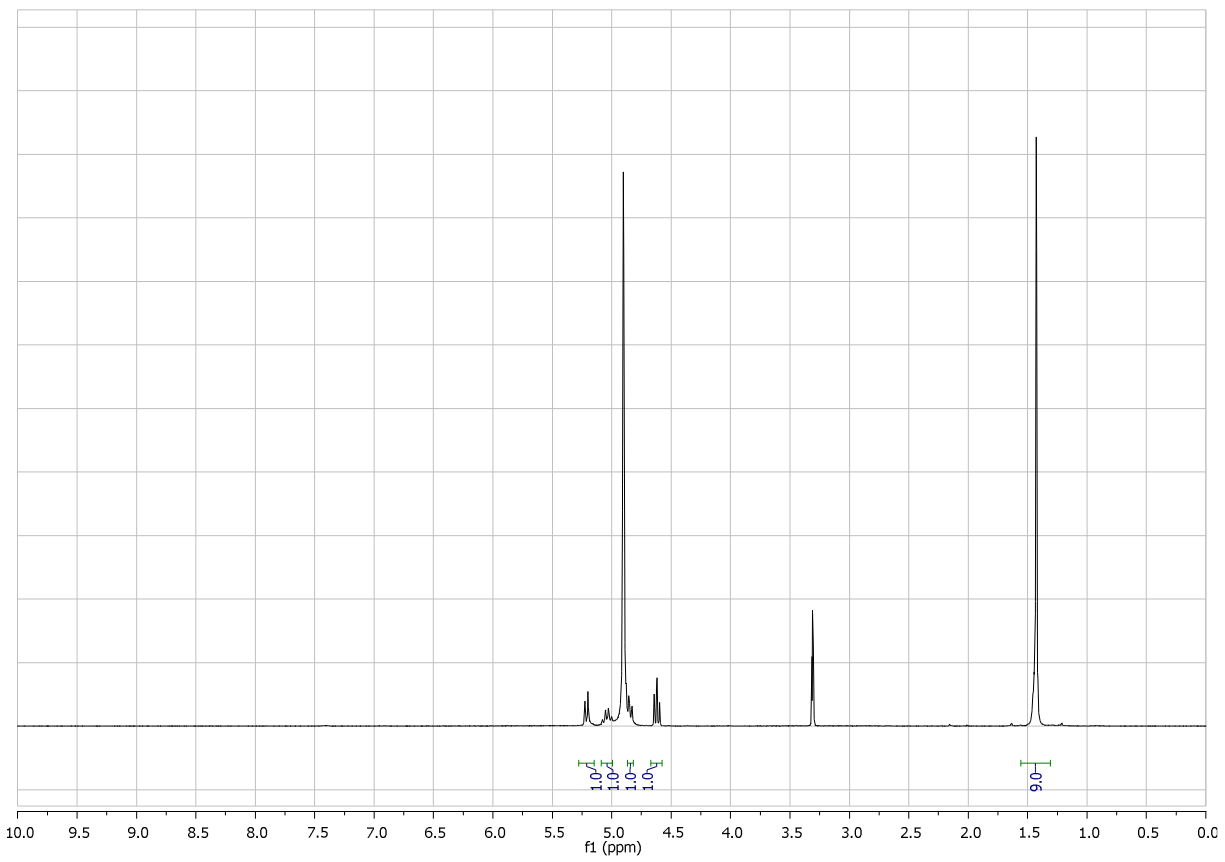


(2R,3R)-3-((tert-butoxycarbonyl)amino)oxetane-2-carboxylic acid (prepared according to Scheme 5)

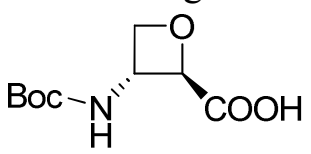

$(+)-9 b$

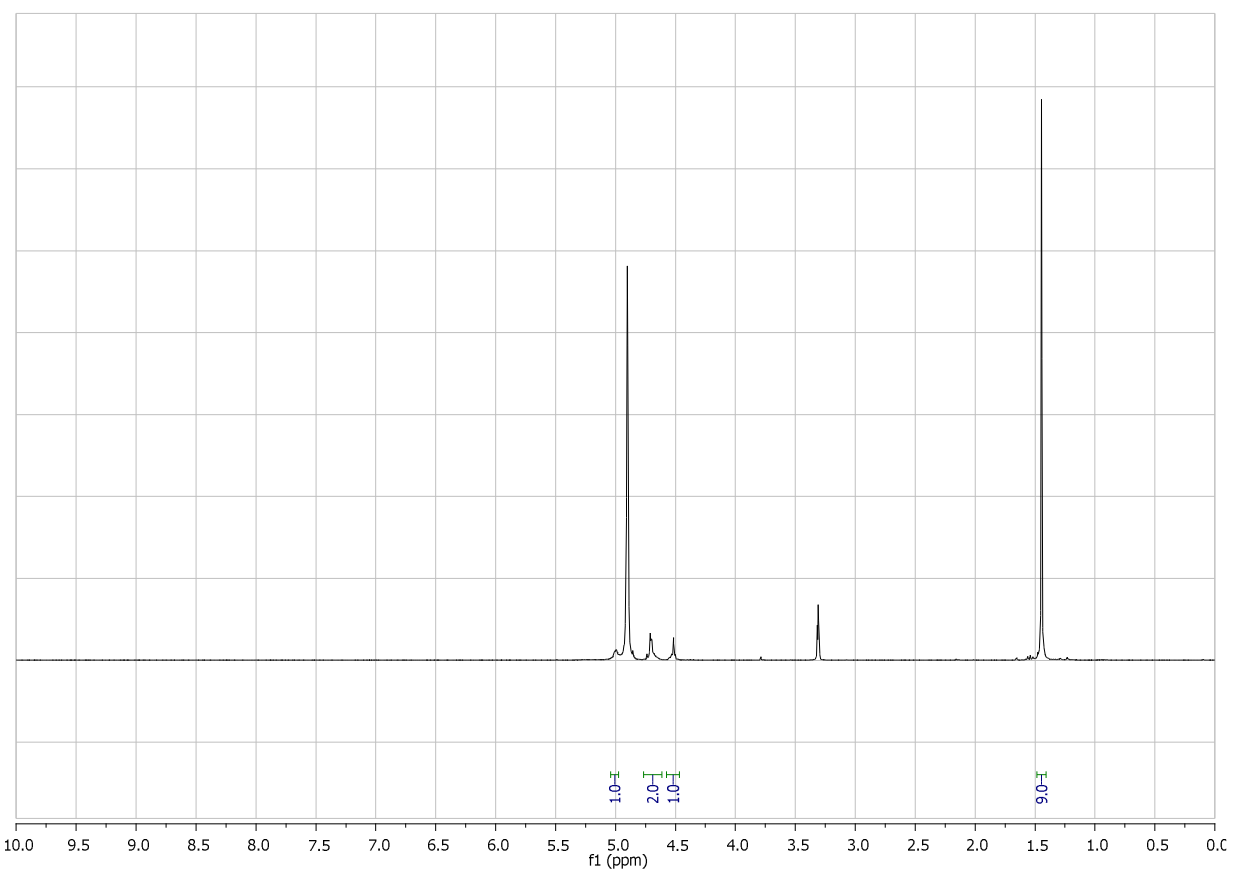

(2S,3S)-3-((tert-butoxycarbonyl)amino)oxetane-2-carboxylic acid (prepared according to Scheme 5)<smiles>CC(C)(C)OC(=O)N[C@H]1CO[C@H]1C(=O)O</smiles>
$(-)-9 b$

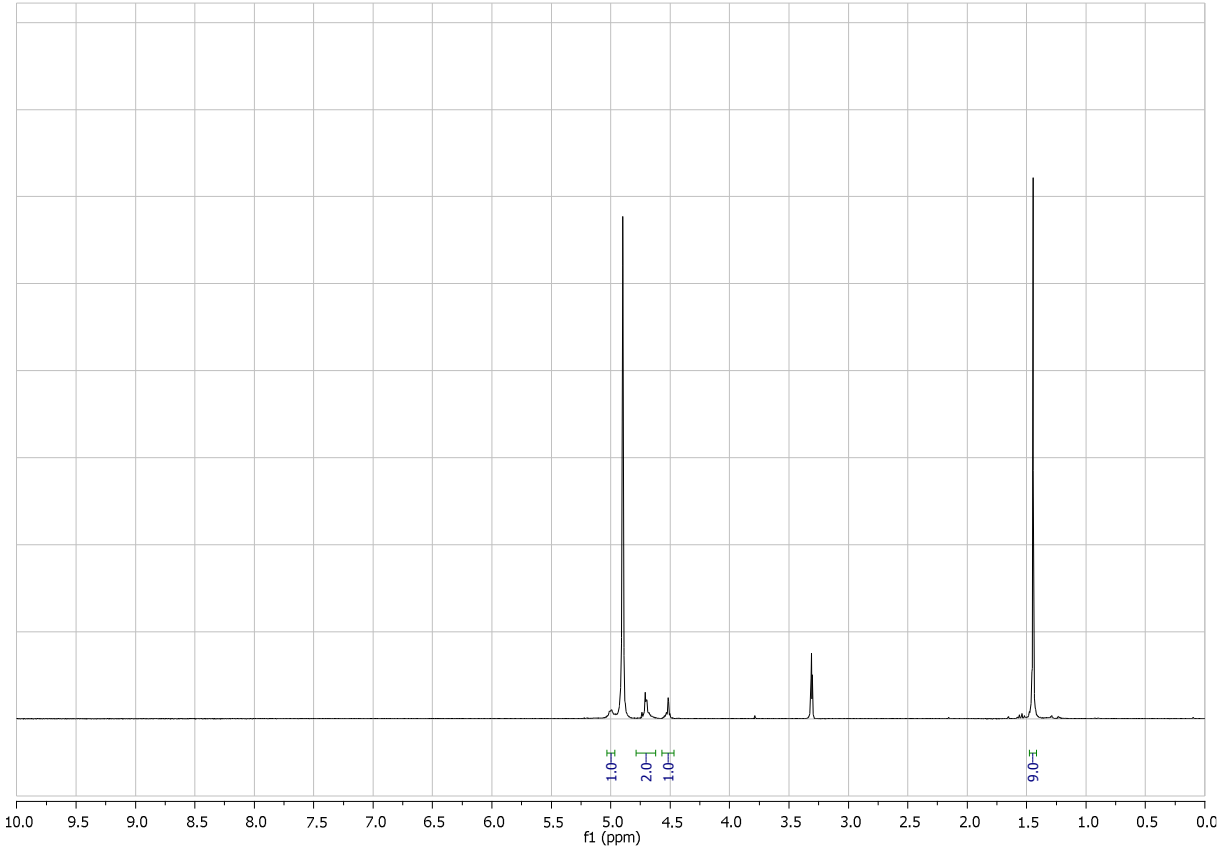




\section{X-ray structure analysis of compounds $12 \mathrm{ab2}$ and $12 \mathrm{bb2}$}

X-ray diffraction data for compounds 12ab2 (CCDC 1491706) and 12bb2 (CCDC 1491705) were collected on a commercial diffractometer using $\mathrm{Mo}_{\mathrm{K} \alpha}$ or $\mathrm{Cu}_{\mathrm{Ka}}$ radiation. In each case, a crystal was mounted on a cryogen-cooled support and flash-frozen in a nitrogen gas stream; the temperature of the crystal was maintained at $100 \pm 1 \mathrm{~K}$. Data were corrected for Lorentz polarization and absorption effects. The structures were solved by direct methods using SHELXS-97 ${ }^{1}$ and refined against $F^{2}$ by full-matrix least-squares techniques using SHELXL-2014 ${ }^{2}$ with anisotropic displacement parameters for all non-hydrogen atoms. Hydrogen atoms were located on a difference Fourier map and introduced into the calculations as a riding model with isotropic thermal parameters. All calculations were performed by using the Crystal Structure crystallographic software package WINGX. ${ }^{3}$

The crystal data collection and refinement parameters are given in Table S1. ORTEP drawings of the molecules are shown in Figures S1 and S2.

CCDC 1491705-1491706 contains the supplementary crystallographic data for this paper. These data can be obtained free of charge from the Cambridge Crystallographic Data Centre via http://www.ccdc.cam.ac.uk/Community/Requestastructure.

1) Sheldrick, G. M. SHELXS-97, Program for Crystal Structure Solution, University of Göttingen, Göttingen, Germany, 1997.

2) Sheldrick, G. M. Acta Crystallogr. A 2008, 64, 112-122.

3) Farrugia, L. J. J. Appl. Cryst. 1999, 32, 837. 
Table S1. Crystallographic data and structure refinement details for compounds 12ab2 and $\mathbf{1 2 b b 2 .}$

\begin{tabular}{|c|c|c|}
\hline Compound & $12 \mathbf{a b 2}$ & $12 b b 2$ \\
\hline CCDC numbers & 1491706 & 1491705 \\
\hline Empirical formula & $\mathrm{C}_{19} \mathrm{H}_{24} \mathrm{~N}_{2} \mathrm{O}_{6}$ & $\mathrm{C}_{19} \mathrm{H}_{24} \mathrm{~N}_{2} \mathrm{O}_{6}$ \\
\hline$M_{r}$ & 376.40 & 376.40 \\
\hline Crystal size, $\mathrm{mm}$ & $0.40 \times 0.14 \times 0.10$ & $0.25 \times 0.03 \times 0.02$ \\
\hline Crystal system & orthorhombic & monoclinic \\
\hline Space group & $P 22_{1} 2_{1} 2_{1}$ & $P 2_{1}$ \\
\hline $\mathrm{a}, \AA$ & $7.1423(3)$ & $9.2191(3)$ \\
\hline $\mathrm{b}, \AA$ & $10.4505(5)$ & $6.1121(2)$ \\
\hline $\mathrm{c}, \AA$ & $25.2828(11)$ & $16.3411(6)$ \\
\hline$\alpha,{ }^{\circ}$ & 90 & 90 \\
\hline$\beta,{ }^{\circ}$ & 90 & $90.496(2)$ \\
\hline$\gamma,{ }^{\circ}$ & 90 & 90 \\
\hline Cell volume, $\AA^{3}$ & $1887.12(15)$ & $920.75(5)$ \\
\hline $\mathrm{Z} ; \mathrm{Z}$ & $4 ; 1$ & $2 ; 1$ \\
\hline$T, \mathrm{~K}$ & $100(1)$ & $100(1)$ \\
\hline Radiation type ; wavelength $\AA$ & $\operatorname{MoK} \alpha ; 0.71073$ & $\mathrm{CuK} \alpha ; 1.54178$ \\
\hline $\mathrm{F}_{000}$ & 800 & 400 \\
\hline$\mu, \mathrm{mm}^{-1}$ & 0.099 & 0.846 \\
\hline$\theta$ range, $^{\circ}$ & $2.529-30.577$ & $2.704-59.009$ \\
\hline Reflections collected & 52959 & 13063 \\
\hline Reflections unique & 5781 & 2599 \\
\hline $\mathrm{R}_{\text {int }}$ & 0.0388 & 0.0942 \\
\hline GOF & 1.056 & 1.048 \\
\hline Refl. obs. $(I>2 \sigma(I))$ & 5371 & 2224 \\
\hline Parameters & 248 & 248 \\
\hline$w_{2}$ (all data) & 0.0832 & 0.1081 \\
\hline $\mathrm{R}$ value $(I>2 \sigma(I))$ & 0.0347 & 0.0534 \\
\hline $\begin{array}{l}\text { Largest diff. peak and hole } \\
\qquad\left(\mathrm{e}^{-} . \AA^{-3}\right)\end{array}$ & $0.259 ;-0.269$ & $0.210 ;-0.227$ \\
\hline
\end{tabular}




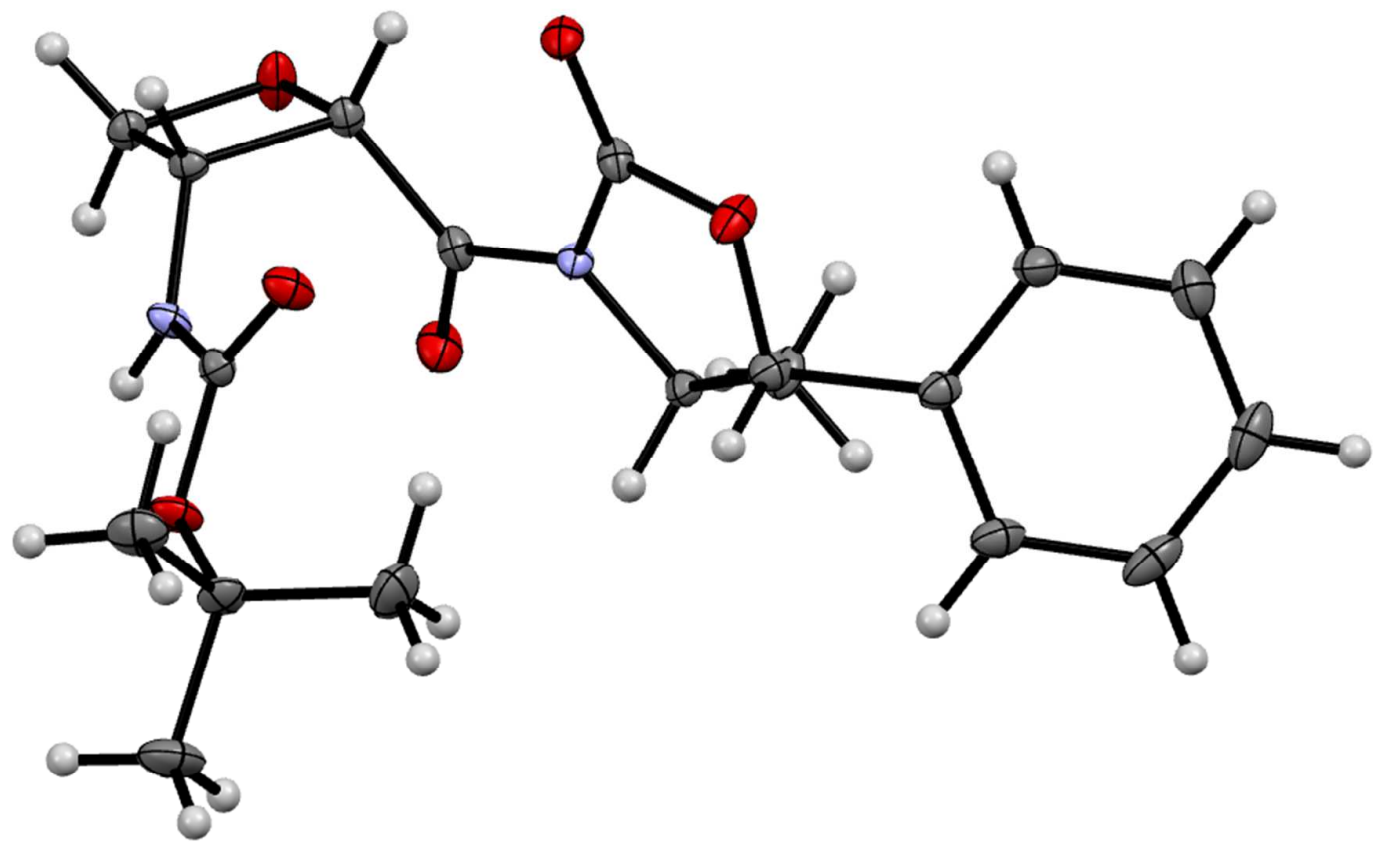

Figure S1: ORTEP drawing (50\% probability thermal ellipsoids) of 12ab2

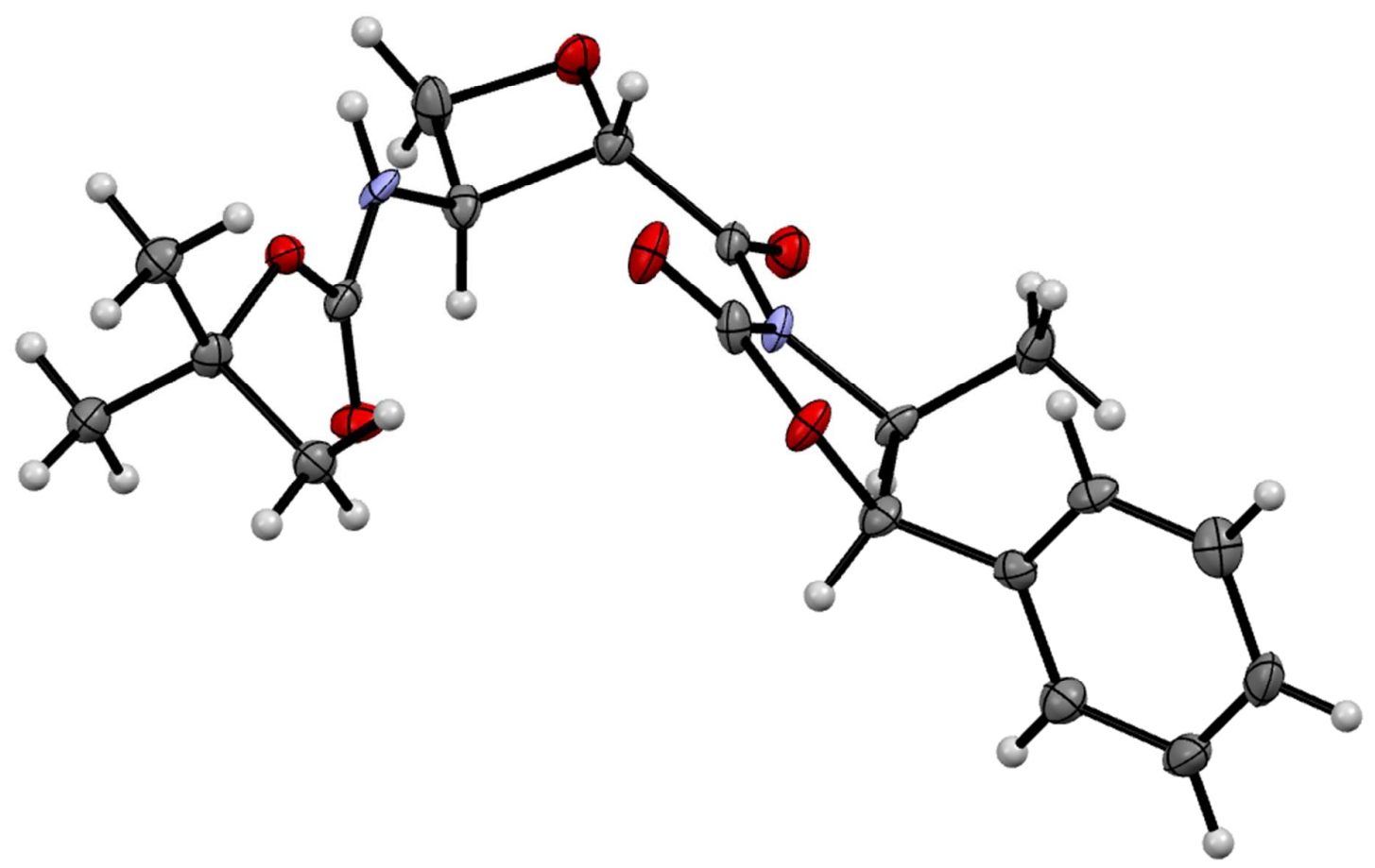

Figure S2: ORTEP drawing (50\% probability thermal ellipsoids) of $12 \mathrm{bb2}$ 


\section{Chiral HPLC chromatograms}

HPLC analysis of $\mathbf{8 a}$ :

5mL/min; 80/20 hexane/iPrOH; concentration: $5 \mathrm{mg} / \mathrm{mL}$; injection: $5 \mu \mathrm{L}$
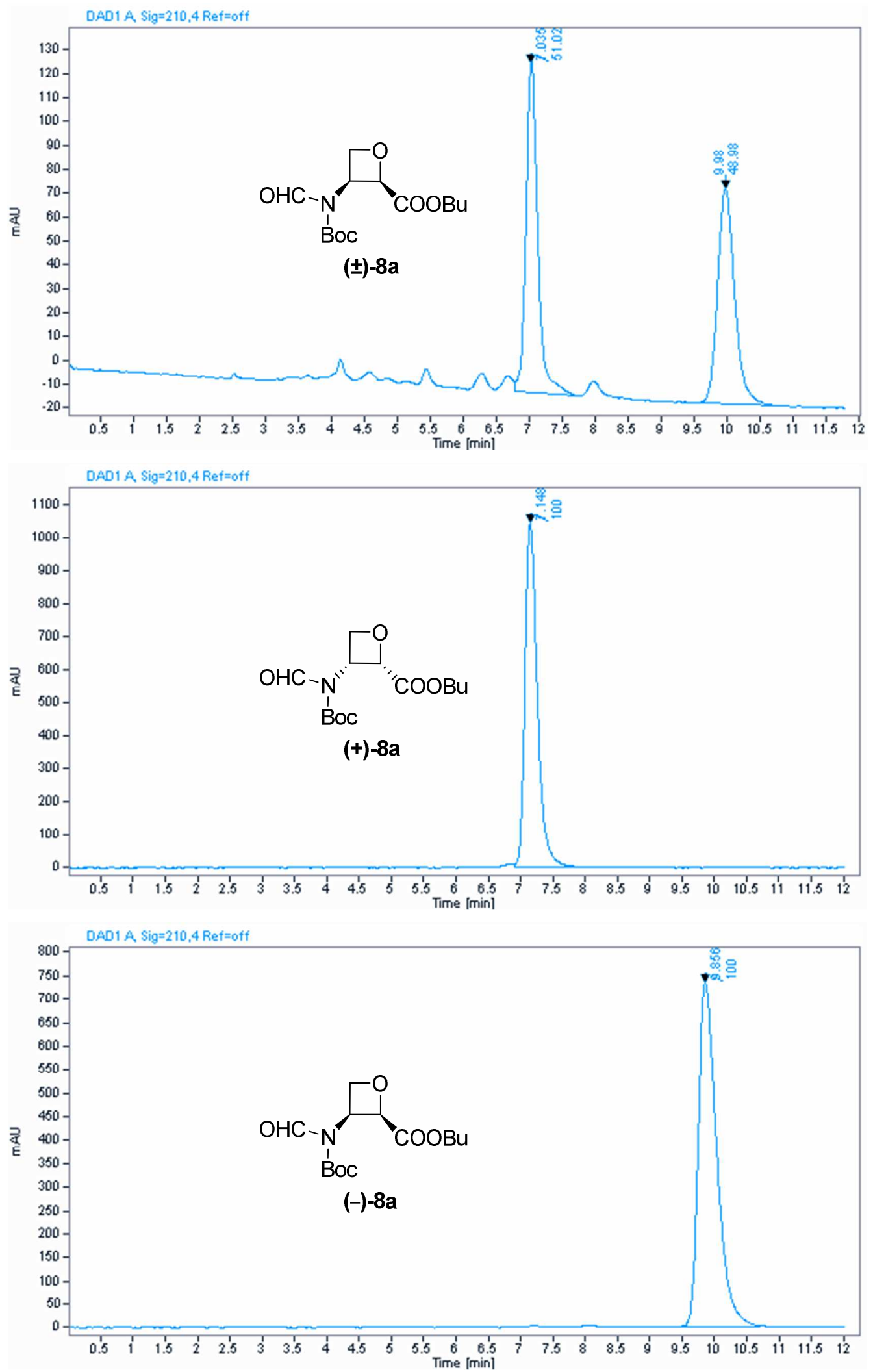
HPLC analysis of $\mathbf{8 b}$ :

5mL/min; 80/20 hexane/iPrOH; concentration: $5 \mathrm{mg} / \mathrm{mL}$; injection: $5 \mu \mathrm{L}$
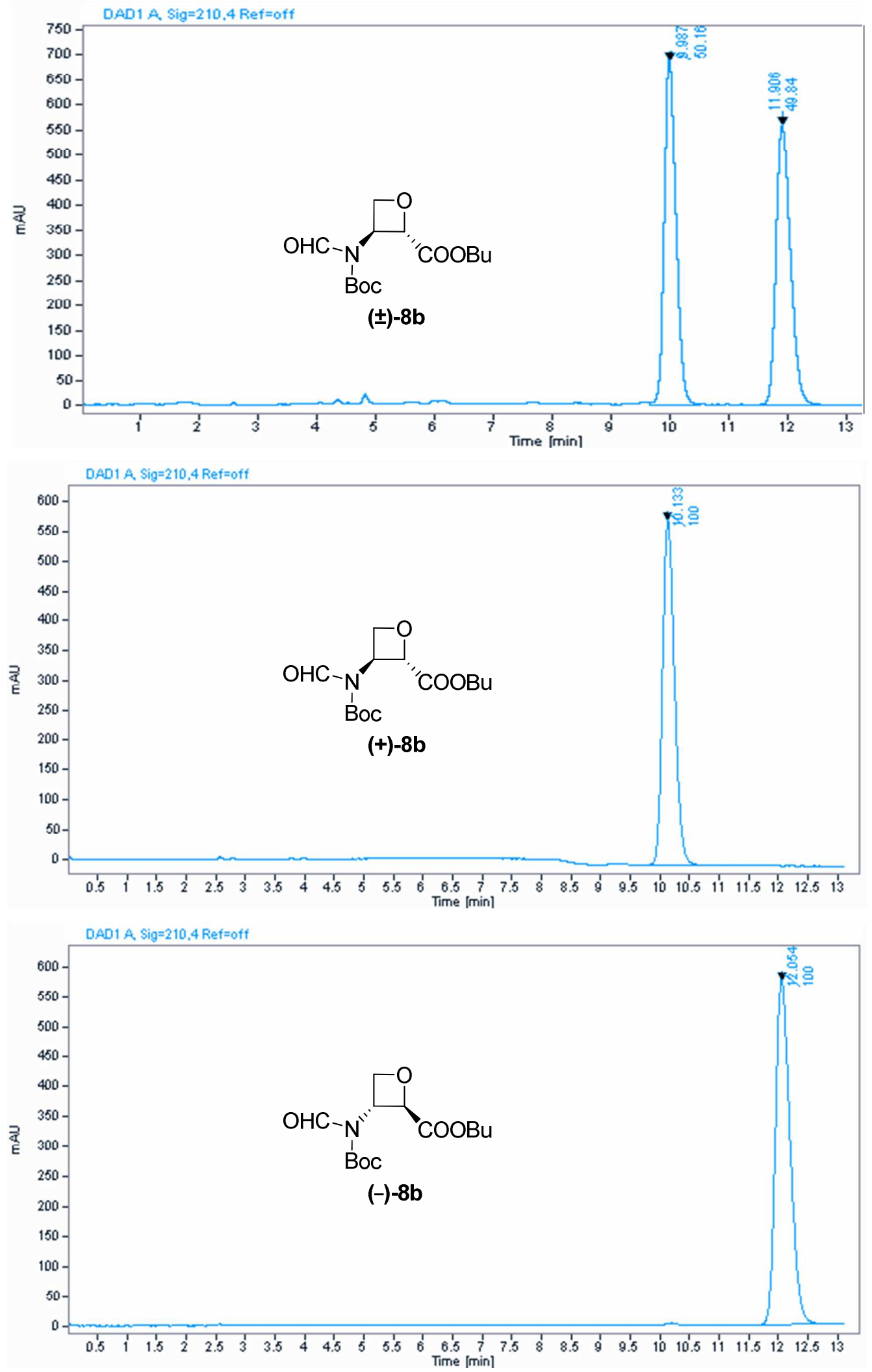
HPLC separation of $\mathbf{8 a}$ :

$5 \mathrm{~mL} / \mathrm{min}$; 80/20 hexane/ $\mathrm{PrOH}$; concentration: $500 \mathrm{mg} / \mathrm{mL}$; injection: $100 \mu \mathrm{L}$

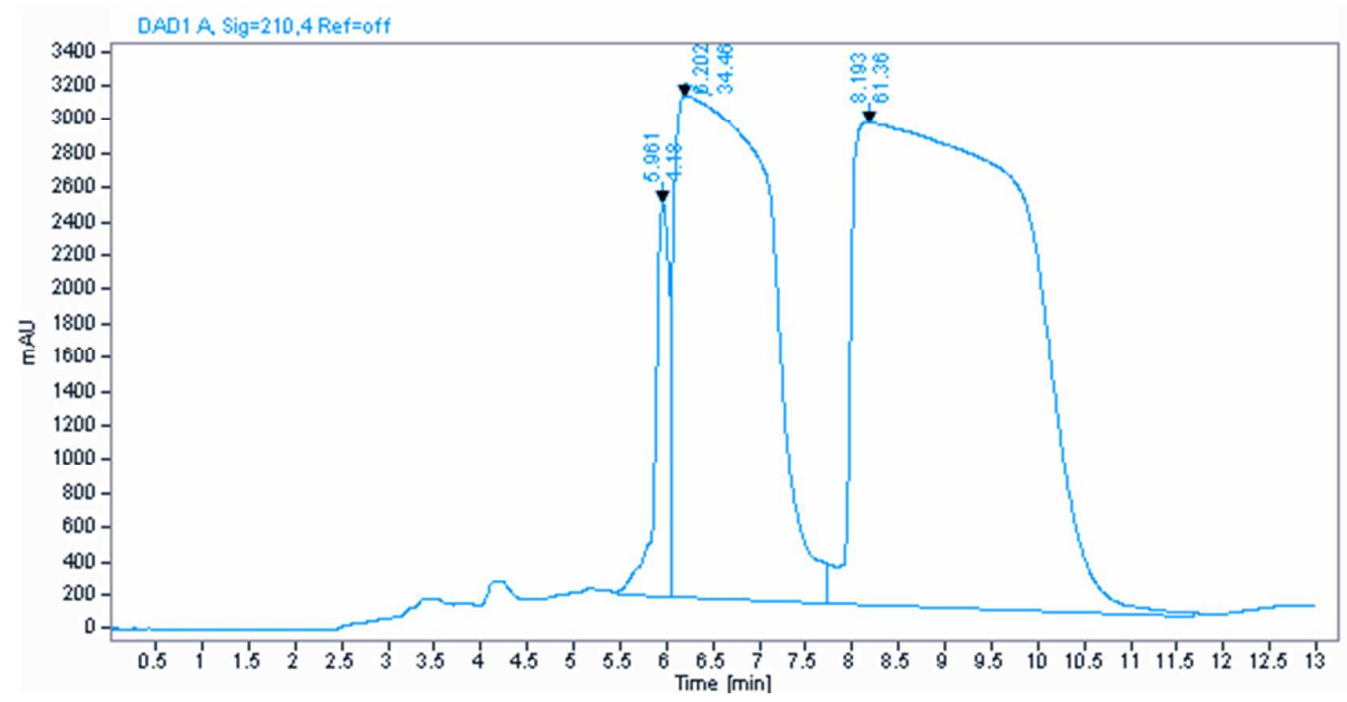

HPLC separation of $\mathbf{8 b}$ :

5mL/min; 80/20 hexane/EtOH; concentration: $500 \mathrm{mg} / \mathrm{mL}$; injection: $75 \mu \mathrm{L}$

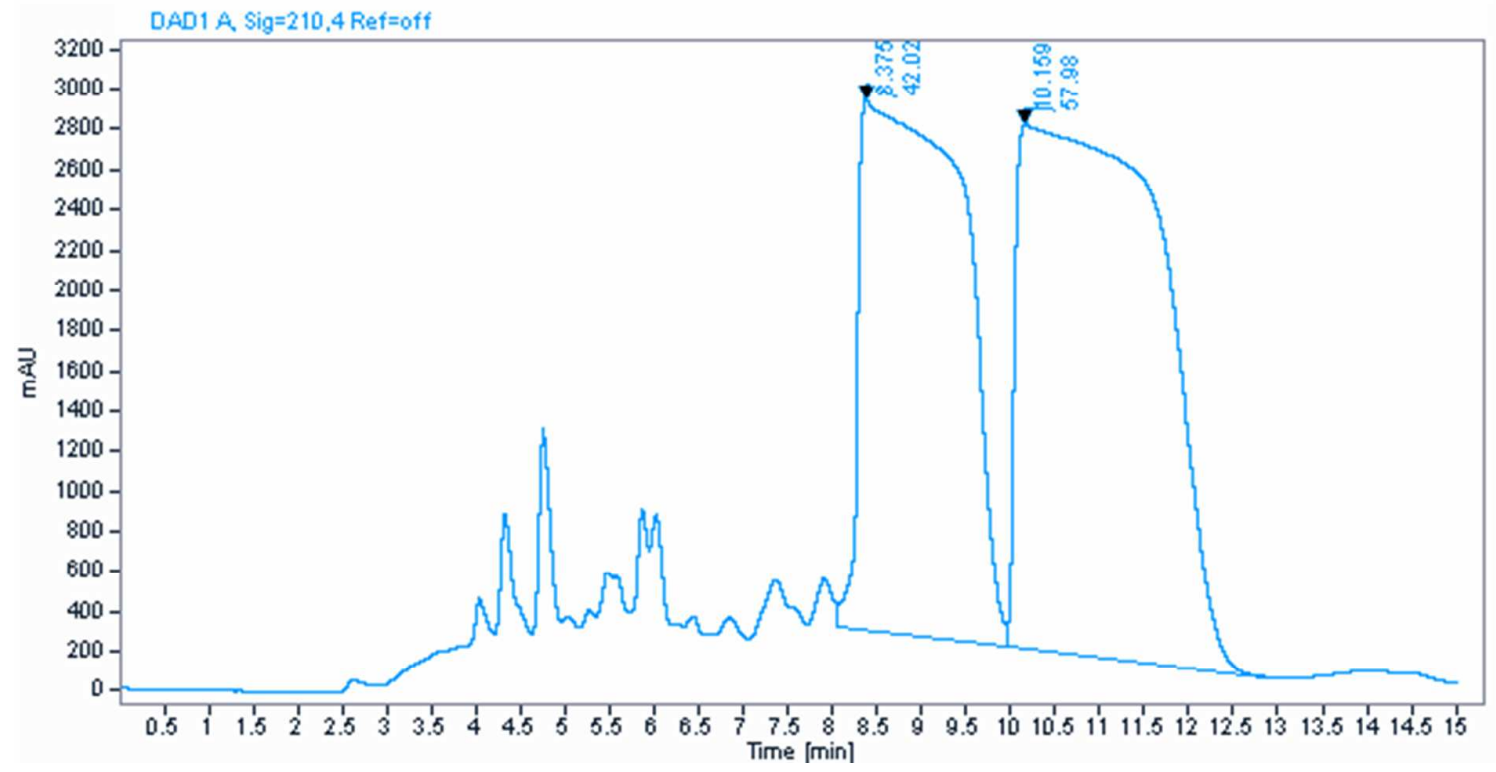

